\title{
The Medullary Targets of Neurally Conveyed Sensory Information from the Rat Hepatic Portal and Superior Mesenteric Veins
}

\author{
Cinthia Garcia-Luna, ${ }^{1, *}$ Graciela Sanchez-Watts,, ${ }^{1, *}$ Myrtha Arnold, ${ }^{2}$ @ Guillaume de Lartigue, ${ }^{3}$ \\ Nick DeWalt, ${ }^{4}$ Wolfgang Langhans, ${ }^{2}$ and Alan G. Watts ${ }^{1,2}$
}

https://doi.org/10.1523/ENEURO.0419-20.2021

${ }^{1}$ The Department of Biological Sciences, USC Dornsife College of Letters, Arts and Sciences, University of Southern California, Los Angeles, CA 90089, ${ }^{2}$ Physiology and Behavior Laboratory, Eidgenössische Technische Hochschule Zürich, Schwerzenbach 8603, Switzerland, ${ }^{3}$ Department of Pharmacodynamics, University of Florida, Gainesville, FL 32611 , and ${ }^{4}$ Yale University, New Haven, CT 06520

\begin{abstract}
Vagal and spinal sensory endings in the wall of the hepatic portal and superior mesenteric veins (PMV) provide the brain with chemosensory information important for energy balance and other functions. To determine their medullary neuronal targets, we injected the transsynaptic anterograde viral tracer HSV-1 H129-772 (H129) into the PMV wall or left nodose ganglion (LNG) of male rats, followed by immunohistochemistry (IHC) and high-resolution imaging. We also determined the chemical phenotype of $\mathrm{H} 129$-infected neurons, and potential vagal and spinal axon terminal appositions in the dorsal motor nucleus of the vagus (DMX) and the nucleus of the solitary tract (NTS). PMV wall injections generated H129-infected neurons in both nodose ganglia and in thoracic dorsal root ganglia (DRGs). In the medulla, cholinergic preganglionic parasympathetic neurons in the DMX were virtually the only targets of chemosensory information from the PMV wall. H129-infected terminal appositions were identified on H129-infected somata and dendrites in the DMX, and on H129-infected DMX dendrites that extend into the NTS. Sensory transmission via vagal and possibly spinal routes from the PMV wall therefore reaches DMX neurons via axo-somatic appositions in the DMX and axo-dendritic appositions in the NTS. However, the dearth of H129-infected NTS neurons indicates that sensory information from the PMV wall terminates on DMX neurons without engaging NTS neurons. These previously underappreciated direct sensory routes into the DMX enable a vago-vagal and possibly spino-vagal reflexes that can directly influence visceral function.
\end{abstract}

Key words: dorsal vagal complex; spinal cord; vagus nerve

\section{Significance Statement}

Vagal and spinal sensory nerves transmit chemosensory information from the hepatic portal and superior mesenteric veins (PMV) to the brain, eliciting central responses to control energy balance. The chemosensory signals are processed in the dorsal vagal complex (DVC), but the precise locations of PMV wall sensory terminals in the brain are unknown. Using the transsynaptic anterograde viral tracer HSV-1 H129, we identify a neuronal group that receive PMV wall chemosensory information: cholinergic neurons in the dorsal motor nucleus of the vagus (DMX) innervated by vagal and possibly spinal sensory inputs. These results provide the foundation for vago-vagal and spino-vagal chemosensory reflexes originating in the PMV wall.

Received September 21, 2020; accepted January 12, 2021; First published January 25, 2021.

The authors declare no competing financial interests.
Author contributions: M.A., W.L., and A.G.W. designed research; C.G.-L., G.S.-W., M.A., G.d.L., N.D., and A.G.W. performed research; C.G.-L. and G.S.-W. analyzed data; C.G.-L., G.S.-W., and A.G.W. wrote the paper. 


\section{Introduction}

The superior mesenteric vein (SMV), gastric vein (GV), and splenic vein (SV) form the venous system that provides the liver with nutrient-rich blood from the intestines, together with blood from the gallbladder, spleen, and parts of the pancreas and stomach. All of these veins drain into the hepatic portal vein (HPV), which then enters the liver. Various molecules, hormones, and ions have been infused into the HPV and their subsequent effects ascribed to spinal and vagal sensory nerve endings in the HPV wall, which then transmits this information to the brain. This mixture of sensory information includes: glucose (Niijima, 1969, 1989; Donovan et al., 1991a,b, 1994; Hamilton-Wessler et al., 1994; Niijima, 1996; Hevener et al., 1997), lipids (Randich et al., 2001; Cox et al., 2004), proteins (Mithieux et al., 2005; Duraffourd et al., 2012), amino acids (Niijima and Meguid, 1995), and ions (Morita et al., 1990; Bourque, 2008; Morita and Abe, 2011), leptin (Shiraishi et al., 1999), GLP-1 (Nakabayashi et al., 1996; Vahl et al., 2007), and CCK (Horn and Friedman, 2004). However, it is not entirely clear for all these substances that the HPV wall is the primary sensory site as opposed to the liver or a posthepatic site. Nonetheless, Saberi et al. (2008) have shown that HPV wall sensory endings extend into the SMV, thereby revealing that a key peripheral glucosensor is present in the walls of the hepatic portal and superior mesenteric veins (PMV) and transmits its information to the brain.

Vagal and spinal chemosensors in the PMV wall play key roles in several physiologic functions, including the control of glycemia and eating. In particular, they are implicated in initiating habitual meals in response to the premeal decline in glycemia (Campfield and Smith, 2003), and they are key components of the brain mechanisms that control sympathoadrenal responses to hypoglycemia in a rate-dependent manner (Donovan and Watts, 2014). Vagal sensory endings in the HPV wall originate primarily in the left nodose ganglion (LNG) and then run through its common hepatic branch (Berthoud, 2004). Spinal sensory endings derive from lower thoracic dorsal root ganglia (DRGs; T8-T13) and run via the splanchnic nerve through the celiac-superior mesenteric ganglion before reaching

This work was supported by National Institutes of Health (NIH) Grants R01s DK118910 and DK121531 (to A.G.W.), the Swiss National Science Foundation Grant IZK0Z3_158027 (to A.G.W. and W.L.), the Consejo Nacional de Ciencia y Tecnología Postdoctoral Fellowship 266700 (to C.G.-L.), and NIH Grants R00 DK094871 and R01 DK116004 (to G.d.L.).

${ }^{*}$ C.G.-L. and G.S.-W. made equal contributions to this study.

Acknowledgements: We thank Jason Junge and Scott Fraser (University of Southern California Translational Imaging Center and University of Southern California Office of the Provost) for their technical and scientific assistance with the super-resolution confocal microscopy imaging. We also thank the Center for Neuroanatomy with Neurotropic Viruses (supported by National Institutes of Health Grant P40 OD010996) for supplying the HSV-1 H129. The late Tim Bartness (Georgia State University) provided much technical assistance during the early stages of this project.

Correspondence should be addressed to Alan G. Watts at watts@usc.edu.

https://doi.org/10.1523/ENEURO.0419-20.2021

Copyright (C) 2021 Garcia-Luna et al.

This is an open-access article distributed under the terms of the Creative Commons Attribution 4.0 International license, which permits unrestricted use, distribution and reproduction in any medium provided that the original work is properly attributed. the PMV wall (Barja et al., 1983; Fujita and Donovan, 2005; Bohland et al., 2014).

Interoceptive signals are processed and integrated with other signals by neurons in the dorsal vagal complex (DVC), particularly the nucleus of the solitary tract (NTS) and the area postrema (AP; Rogers and Hermann, 1983; Menétrey and Basbaum, 1987; Rinaman et al., 1989; Rinaman and Schwartz, 2004). Although the NTS has been proposed as the key termination zone for sensory information from the HPV wall (Kobashi and Adachi, 1986; Morita et al., 1997), the detailed organization of the termination points of PMV wall sensory information in the brain remains unknown.

Conventional monosynaptic tracers are limited in their ability to identify hierarchically arranged synaptic connections within a network. Therefore, transsynaptic tracers are required to reveal the brain network associated with a specific target organ. The Herpes simplex virus- 1 H129 is currently the only known transsynaptic viral tracer whose infection propagates predominantly in an anterograde direction (Archin and Atherton, 2002; Wojaczynski et al., 2015). It has therefore proved to be very effective for defining how sensory pathways from the stomach (Rinaman and Schwartz, 2004; Horn et al., 2014), adipose tissue (Song et al., 2009; Ryu et al., 2017), and trachea (McGovern et al., 2012, 2015) distribute within the brain.

We have taken advantage of these properties of $\mathrm{H} 129$ to determine the medullary targets of the chemosensory information that flows through the PMV vasculature. To do this we injected H129 into the wall of the HPV and SMV. The vagal sensory neurons that innervate the PMV originate in the LNG (Berthoud, 2004), and so we also injected H129 into the LNG of a separate group of animals. We did this to help identify how sensory nerves from the PMV wall relate to the population of vagal sensory neurons as a whole. These LNG injected animals were allowed to survive for between 1 and $3 \mathrm{~d}$, thereby helping us to characterize $\mathrm{H} 129$ infection rates and patterns in the DVC. We then used double-immunohistochemistry (IHC) and triple-IHC followed by super-resolution confocal microscopy and 3D image analyses to identify the locations and chemical phenotype of infected neurons, the co-occurrence of $\mathrm{H} 129$ with neurochemical markers, and the nature and location of $\mathrm{H} 129$ terminal appositions in the DVC.

\section{Materials and Methods}

\section{Animals}

Sixty-seven adult male Sprague Dawley rats (Charles River) were used. At the time of surgery, they weighed between 211 and $330 \mathrm{~g}$ (mean $264 \pm 3 \mathrm{~g}$ ). They were housed two or three per cage in a climate-controlled environment (temperature $21 \pm 1^{\circ} \mathrm{C}, 55 \pm 5 \%$ relative humidity), on a 12/12 h light/dark cycle (zeitgeber time $0=11$ P.M.) with unrestricted access to food (Standard laboratory chow, KLIBA 3433) and tap water for $10 \mathrm{~d}$ to allow adaptation to the housing conditions. Postsurgical animals were offered wet mash food in addition to chow. All animal procedures were approved by the Zurich Cantonal Veterinary Office. 


\section{Surgical procedures}

All animals were anesthetized with an isoflurane/oxygen mixture, and body temperature maintained between $37^{\circ} \mathrm{C}$ and $38^{\circ} \mathrm{C}$ throughout surgery with a heating pad. Atropine $(0.05 \mathrm{mg} / \mathrm{kg})$ was administered in the immediate presurgery period, and carprofen was administered postsurgery and on the following three days as an analgesic.

All animals were injected with herpes simplex virus-1 H129-772 (H129; The Center for Neuroanatomy with Neurotropic Viruses, Princeton University) engineered so that infected cells express enhanced green fluorescent protein (eGFP). All injections were made using a titer of between 8 and $9 \times 10^{8} \mathrm{pfu} / \mathrm{ml}$. The injectate contained $5 \%$ E133 (blue) food dye to ensure accurate placement into all targeted sites. All experimental and animal housing procedures involving $\mathrm{H} 129$ were performed using Biosafety Level 2 requirements.

Animals were initially divided into four groups: those with $\mathrm{H} 129$ injected into the wall of the PMV $(n=44)$, two control groups injected with $\mathrm{H} 129$ in the PMV lumen $(n=6)$, or onto the PMV surface $(n=5)$, and those injected with H129 into the LNG $(n=12)$. The PMV wall, the PMV lumen and the PMV surface groups were assigned either 96- or 120-h survival time; the LNG group was divided into 24-, 48-, or 72-h survival time (each $n=4$ ). Survival times were based on those of Rinaman and Schwartz (2004), and on the difference in the distance needed for $\mathrm{H} 129$ to travel from the LNG or PMV into the medulla.

\section{LNG H129 injections}

Virus injections into the LNG was performed as previously described (Krieger et al., 2016, 2018; Lee et al., 2020). Briefly, a midline incision was made, and salivary glands, lymph nodes, sternohyoid, and omohyoid muscles were retracted to expose the trachea and carotid artery. The vagus nerve was separated from the carotid artery by blunt dissection until the LNG became accessible, and 0.9-1.2 $\mu$ of $\mathrm{H} 129$ was injected using a glass capillary micropipette attached to a microinjector (Picospritzer III injector; Parker Hannifin; Fig. 1A,B). Results from the LNG-injections described here are from a group of animals that were also used in a previous study (Krieger et al., 2018).

\section{PMV wall H129 injections}

The PMV caudal to the porta hepatis was exposed and made accessible by way of a $5-\mathrm{cm}$ skin incision in the rostral-caudal midline using a procedure similar to one for implanting HPV catheters (Arnold et al., 2012). The skin was separated by blunt dissection from the underlying muscle, and a $5 \mathrm{~cm}$ laparotomy was made beneath the skin incision. The small and large intestines were exteriorized, placed on the animals left side, and covered with a warm-saline-moistened gauze. The liver was retracted toward the diaphragm and secured with a piece of wet gauze.

The target sites in the PMV wall were carefully manipulated and elevated with fine forceps. A glass capillary micropipette containing $\mathrm{H} 129$ was introduced into the PMV wall parallel to the lumen and directed toward that porta hepatis. H129 was then injected into various sites of the PMV wall using a microinjector (Picospritzer III injector;
Parker Hannifin). Four sets of injections were made to target: (1) the HPV wall between the porta hepatis and GV, $n=13$; (2) the HPV wall between the GV and SV, $n=8$; (3) the proximal SMV wall, $n=8$; and (4) the PMV wall between the porta hepatis and the proximal SMV, $n=15$ (Table 1; Fig. $1 C, D$ ). The various sets of observations from H129 injections in the LNG and PMV wall that we report in the Results were each obtained from at least three animals.

After the designated survival times, rats were anesthetized with isoflurane (IsoFlo; Abbott, Baar, Switzerland) and transcardially perfused with $0.9 \%$ saline followed by pH 9.5 borate-buffered-4\% paraformaldehyde. Brains of all animals, both nodose ganglia and DRGs (T8-T13) of PMV wall animals were excised. Brains were postfixed in borate-buffered- $4 \%$ paraformaldehyde $+15 \%$ sugar for $24 \mathrm{~h}$ at $4^{\circ} \mathrm{C}$, fast frozen in dry ice and stored at $-70^{\circ} \mathrm{C}$ until further processing. Both nodose ganglia, and DRGs were postfixed for $2 \mathrm{~h}$ and cryoprotected in borate-buffered- $4 \%$ paraformaldehyde $+25 \%$ sugar solution for $2 \mathrm{~d}$, before embedding in OCT, frozen with dry-ice and stored at $-70^{\circ} \mathrm{C}$ until further processing.

Four series of frozen brain coronal sections $(30 \mu \mathrm{m})$ were cut throughout the rostrocaudal extent of the DVC, using a sliding microtome, and stored in a cryoprotectant solution $(50 \% 0.05$ m sodium-phosphate buffer, $30 \%$ ethylene glycol, $20 \%$ glycerol) until IHC was performed. Both nodose ganglia, and DRGs were cut at $-20^{\circ} \mathrm{C}$ with a CM1850 cryostat (Leica Microsystems Inc.) in 10- $\mu \mathrm{m} \mathrm{sec-}$ tions (1:4), thaw-mounted onto Superfrost Plus slides and kept at $-70^{\circ} \mathrm{C}$ until IHC was performed.

\section{Immunohistochemistry}

\section{Antibody characterization}

Chicken anti-GFP (eGFP). Ab13970 (Abcam) was used. Manufacturer determined the specificity through the use of immunofluorescence histochemistry, where eGFP-immunoreactivity (-ir) was absent in non-transfected mouse embryo fibroblast $\mathrm{NIH} / 3 \mathrm{~T} 3$ cells compared with that of eGFP-transfected NIH/3T3 cells. Additionally, no eGFP-ir was detected in wild-type BDNF mice cortical cultures in contrast to those transfected with BDNF-eGFP (Wosnitzka et al., 2020).

Mouse anti-dopamine- $\boldsymbol{\beta}$-hydroxylase (DBH). MAB308 (Millipore) was used. The manufacturers reported that western blot analysis recognized a band of $\sim 70 \mathrm{kDa}$ in rat tissue (Bruinstroop et al., 2012). In addition, immunolabeling was abolished following preabsorption with the immunogen (Rinaman, 2001).

Goat anti-choline acetyltransferase (ChAT). AB144P (Millipore) was used. This antibody was raised against the human placental enzyme. The manufacturers reported that western blots of mouse brain lysates showed a band at $\sim 70-74 \mathrm{kDa}$. In the current study, the pattern of labeling seen in the DVC is in accordance to previously described cholinergic cell groups (Ruggiero et al., 1990).

Rabbit anti-synapsin I pSer 62/67 (Synl). AP08742PU$\mathrm{N}$ (Acris Antibodies Inc.) was used. The manufacturers reported that western blot of rat cortical lysates showed immunolabeling of a band at $78 \mathrm{kDa}$, a signal that is blocked 




Figure 1. Experimental design. $\boldsymbol{A}$, Schematic representation of the two sites in male rats injected with the anterograde transsynaptic viral tracer, herpes simplex virus-1 H129 (H129): the LNG $(n=12)$, and the portal/mesenteric veins (PMV; $n=44)$ wall. $\boldsymbol{B}$, A photograph showing an $\mathrm{H} 129$ injection into the LNG. The micropipette injector is visible from the top left corner of the image with its tip in the LNG. The E133 blue dye allows the visualization of the injection. $\boldsymbol{C}$, Schematic representation of the HPV and its accompanying vasculature (adapted from Dong et al., 2010). The HPV is fed by the SMV that drains the small intestine, the GVs from the stomach, and the SV from the spleen, and parts of the pancreas and stomach. H129 injections were placed in the PMV wall at four locations (numbered 1-4) from the porta hepatis to the proximal SMV. Da, A photograph showing the PMV wall regions injected with H129. Note that the SV, which marks the SMV/HPV transition, is only visible by retracting the overlying adipose tissue. It is only seen in this panel. Panels $\boldsymbol{D} \boldsymbol{b}-\boldsymbol{D} \boldsymbol{d}$ show three $\mathrm{H} 129$ injection sites (blue marks in the vein walls, highlighted by the white asterisks). Micropipette injectors are visible in panels $\boldsymbol{b}, \boldsymbol{c}$. Injection sites range from being close to the porta hepatis (bi) to the proximal SMV (c). A group 4 injection is shown in $\boldsymbol{d}$. The numbers in the top right corner of each panel correspond to the four PMV wall injection sites shown in $\boldsymbol{C}$. No image was available for group 2 injections.

by preabsorption with the phospho-peptide used as antigen (manufacturer's information).

Biotinylated Griffonia simplicifolia Lectin I isolectin B4 (IB4). B-1205 (Vector Laboratories) was used. This Isolectin has an appropriate number of biotins bound to provide optimum staining characteristics for this lectin (as per manufacturer's description). This conjugate is supplied essentially free of unconjugated biotins and it is used here as a marker of unmyelinated vagal sensory nerves. 
Table 1: Injection targets in the HPV and SMV walls

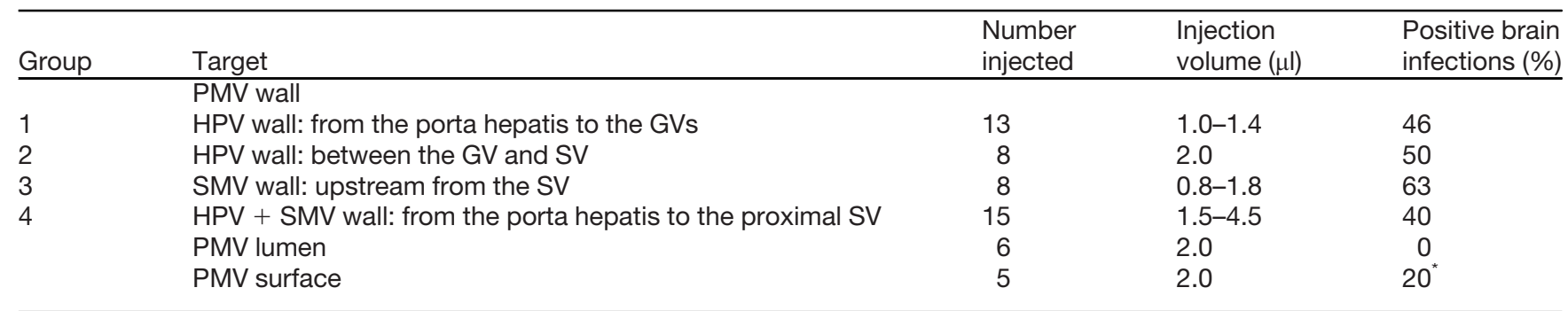

Four regions of the HPV and SMV walls were injected with H129. See Figure 1 for the details of these locations. In addition, two control regions, the HPV lumen and surface were administered with $\mathrm{H} 129$.

* One PMV surface animal showed positive $\mathrm{H} 129$ in the same dorsal medulla regions as the PMV wall injections. However, the injector tip of this animal punctured the surface of the PMV wall, making it likely that $\mathrm{H} 129$ infected the same sensory endings as those animals in the PMV wall groups.

\section{Secondary antibodies}

Donkey anti-chicken IgG-Alexa Fluor 488 (catalog \#703-545-155), donkey anti-mouse IgG-Cyanine 3 (catalog \#715-165-150), donkey anti-goat lgG-cyanine 3 (catalog \#705-165-147), donkey anti-goat IgG-Alexa Fluor 647 (catalog \#705-605-147), donkey anti-rabbit IgG-Alexa Fluor 647 (catalog \#711-605-152), and streptavidin-cyanine 3 (catalog \#434315; Thermo Fisher Scientific, Invitrogen) were used. Unless stated, all secondary antibodies were obtained from Jackson ImmunoResearch. The specificity of all secondary antibodies was assessed by incubating control sections without primary antibodies followed by incubation with the corresponding secondary antibody. None of these control incubations resulted in immunofluorescent labeling.

IHC on brain sections. Brain sections were taken out of cryoprotectant, washed five times for $5 \mathrm{~min}$ each at room temperature in Tris-buffered saline (TBS; $\mathrm{pH} 7.4$ ), and processed for double or triple fluorescent IHC.

Double-IHC: eGFP + IB4. After rinsing in TBS, sections were rinsed in PBS for $10 \mathrm{~min}$, incubated in a PBS-blocking solution containing $2 \%(\mathrm{v} / \mathrm{v})$ normal donkey serum (NDS; Chemicon), 0.2\% (v/v), Triton X-100 (Sigma-Aldrich), and $1 \mathrm{mg} / \mathrm{ml}$ bovine serum albumin (Sigma-Aldrich) for $45 \mathrm{~min}$ at $30^{\circ} \mathrm{C}$. They were then transferred to a cocktail of chicken anti-eGFP (1:5000) and biotinylated IB4 (1:100) diluted in the PBS-blocking solution, incubated for $1 \mathrm{~h}$ at $30^{\circ} \mathrm{C}$, and then transferred to $4^{\circ} \mathrm{C}$ for an overnight incubation. Sections were washed in PBS five times for 5 min each, and incubated at room temperature for $1 \mathrm{~h}$ in a cocktail of donkey anti-chicken IgG-Alexa Fluor 488 (1:500) and streptavidincyanine 3 (1:1000) in the PBS-blocking solution. Sections were again washed in PBS, mounted onto Superfrost Plus slides and allowed to air dry in the dark. Once dry, all slides were coverslipped with an antifade solution of $50 \%$ glycerol/50\% PBS/2\% DABCO (1,4-Diazabicyclo[2.2.2]octane), and stored in the dark at $4^{\circ} \mathrm{C}$.

Triple-IHC: eGFP + DBH + ChAT. After rinsing in TBS, sections were incubated in a blocking solution of TBS $/ 2 \%$ NDS $/ 0.1 \%$ Triton $\mathrm{X}-100$ for $3 \mathrm{~h}$ at room temperature. Sections were transferred to the primary antibody cocktail of chicken anti-eGFP (1:10,000), mouse anti-DBH $(1: 10,000)$, goat anti-ChAT (1:1000) diluted in the TBS-blocking solution, and incubated for $\sim 68 \mathrm{~h}$ at $4^{\circ} \mathrm{C}$. Sections were removed from the primary antibody mix, washed in TBS, and transferred to a secondary antibody cocktail of donkey antichicken IgG-Alexa Fluor 488, donkey anti-mouse IgG- cyanine 3 and donkey anti-goat IgG-Alexa Fluor 647 (all 1:2000) in the TBS-blocking solution, and then incubated overnight at $4^{\circ} \mathrm{C}$. Sections were rinsed in TBS five times for 5 min each, mounted, coverslipped, and stored as described above.

Triple-IHC: eGFP + SynI + IB4. This was accomplished in two consecutive stages: sections were first processed to completion for eGFP-ir and Synl, and then processed for IB4. For the first incubation, sections rinsed and blocked as above in the TBS-blocking solution for $3 \mathrm{~h}$ at room temperature, transferred to a primary antibody cocktail of chicken anti-eGFP $(1: 10,000)$ and rabbit antiSynl $(1: 10,000)$ diluted in the TBS-blocking solution and incubated for $\sim 68 \mathrm{~h}$ at $4^{\circ} \mathrm{C}$. Sections were removed from the primary antibody mix, washed in TBS, and transferred to a secondary antibody cocktail of donkey anti-chicken IgG-Alexa Fluor 488 and donkey anti-rabbit IgG-Alexa Fluor 647 (both 1:2000) in the TBS-blocking solution, and incubated overnight at $4^{\circ} \mathrm{C}$. From here on, sections were processed in the dark to preserve the fluorescent labeling. They were rinsed in TBS five times for $5 \mathrm{~min}$ each, rinsed in PBS for $10 \mathrm{~min}$, then incubated in a blocking solution of the PBS-blocking solution for $45 \mathrm{~min}$ at $30^{\circ} \mathrm{C}$, followed by a $1-\mathrm{h}$ incubation at $30^{\circ} \mathrm{C}$ in a solution of biotinylated IB4 diluted 1:100 in the PBS-blocking solution before being transferred for an overnight incubation at $4^{\circ} \mathrm{C}$. Sections were washed in PBS five times for 5 min each, then incubated at room temperature for $1 \mathrm{~h}$ in a solution of streptavidin-cyanine $3(1: 1000)$ in the PBS-blocking solution. Sections were washed in PBS, mounted, coverslipped, and stored as described above.

Nodose and DRGs IHC: eGFP + ChAT. Slides were warmed up to room temperature, placed on a hotplate for $5 \mathrm{~min}$ at $35^{\circ} \mathrm{C}$, rehydrated in TBS for $5 \mathrm{~min}$, then incubated in the TBS-blocking solution for $2 \mathrm{~h}$ at room temperature. Slides were transferred to a primary antibody cocktail of chicken anti-eGFP (1:5000) and goat anti-ChAT (1:500) diluted in the TBS-blocking solution, incubated for $\sim 24 \mathrm{~h}$ at $4^{\circ} \mathrm{C}$. Slides were removed from the primary antibody mix, washed in TBS, and transferred to a secondary antibody cocktail of donkey anti-chicken IgG-Alexa Fluor 488 (1:500), and donkey anti-goat IgG-cyanine 3 (1:500) in the TBS-blocking solution, and incubated overnight at $4^{\circ} \mathrm{C}$. Slides were then rinsed in TBS five times for $5 \mathrm{~min}$ each, allowed to dry in the dark, coverslipped using 50\% glycerol $/ 50 \% \mathrm{PBS} / 2 \% \mathrm{DABCO}$, and stored in the dark at $4{ }^{\circ} \mathrm{C}$ 


\section{Image acquisition}

Epifluorescence imaging

Each of the selected fields within a section was imaged by acquiring tiled low-power scans that captured each fluorescent channel and the corresponding darkfield illumination resulting in up to four images per section. Image acquisition used a motorized Zeiss Axiolmager Z1 microscope (Carl Zeiss Microlmaging Inc.) equipped with a Hammamatsu Orca ER camera using Fluar $5 \times$ (numerical aperture 0.25) and Plan Apochromat $10 \times$ (numerical aperture 0.45 ) objectives. Both the image capture and tiling processes (using a 10\% overlap between neighboring tiles) was controlled by Volocity software (version 6.1; PerkinElmer). Adobe Photoshop 2020 (Adobe Systems Inc.) was used postcapture to create composite images, including whole image contrast and/or brightness modifications where appropriate.

\section{Confocal imaging}

High-power confocal Z-stack tile images were captured using a LSM700 Confocal Laser Scanning Microscope controlled by Zeiss Zen software using Plan Apochromat $20 \times$ (numerical aperture 0.8) and EC Plan-Neofluar 40x oil-corrected (numerical aperture 1.3) objectives. Images were taken using a unidirectional line scan at $1024 \times 1024$ pixels captured on an eight-bit gray scale. Each pixel was scanned twice and the result was averaged to reduce optical noise. Appropriate emission filters were applied to prevent bleed-through between optical channels. Images were stitched with Zen software using a 10\% overlap between frames. 2D flatten confocal Z-stack images were constructed by maximum intensity projection and by taking images through the $z$-axis with a frequency of $5 \mu \mathrm{m}$ throughout the entire depth of the tissue section $(30 \mu \mathrm{m})$. Images were contrast-enhanced using Adobe Photoshop 2020 , and then used to create a composite image including two or three fluorescent channels.

Super-resolution confocal microscopy. Super-resolution images were captured using a Leica SP8 with DIVE Confocal Laser Scanning Microscope controlled by LAS/X software (Leica Microsystems Inc.) using an HC PL APO $63 \times$ oil-corrected (numerical aperture 1.4) objective. A digital zoom of 2.23 was applied using the LAS/X software to result in an image magnified to $140.5 \times$. Images were taken using a bidirectional line scan at $512 \times 512$ pixels captured on a 16-bit gray scale, each pixel was scanned twice and the result was averaged to reduce optical noise. White light laser tuned to 488-, 561-, and 647-nm excitation and 497- to 519-, 578- to 591-, and 692- to $761-\mathrm{nm}$ collection bandwidths were used to image sequentially. The collection was at $2.5 \times$ Nyquist oversampling for Lightning deconvolution from Leica. 3D images were constructed by taking images of planes through the $z$-axis with a frequency of $0.13 \mu \mathrm{m}$ through a $13-\mu \mathrm{m}$ depth or $0.23 \mu \mathrm{m}$ throughout the entire $30-\mu \mathrm{m}$ depth of the tissue section, using LAS/X software. Contrast enhancement was performed to images using Adobe Photoshop 2020. We analyzed the co-occurrence (Dunn et al., 2011; Johnson et al., 2018) of eGFP, IB4, and Synl in fluorescently-labeled structures in a selected region of interest in the commissural NTS and in the dorsal motor nucleus of the vagus (DMX). We first set thresholds to define specific and background signals, and then we quantified the total number of Synl structures and their mean diameter was calculated using the 3D analysis module of LAS/X software. Subsequently, a threshold of one standard deviation below and above the mean diameter $(0.27-0.98 \mu \mathrm{m})$ was used to build a protocol that identified double-labeled and triple-labeled structures that contained Synl.

\section{Atlas-based mapping}

Tissue sections corresponding to atlas levels (AL) 6373 were analyzed, (Swanson, 2018). The left hemisphere of animals' brain is on the left side of the images. Dark-field photomicrographs of the same sections used to image eGFP, DBH and ChAT immunostaining were produced with a Zeiss Axiolmager Z1 microscope using a Hammamatsu Orca ER camera and controlled by Volocity software. Brightness and contrast adjustments were made with Adobe Photoshop 2020 before mapping, and all photomicrographs, including eGFP, DBH and ChAT immunostaining, and dark-field images, were imported to Adobe Illustrator 2020 (Al). Tracts and anatomical regions were identified and outlined with an overlying layer of the Al file of the corresponding $\mathrm{AL}$, using the dark-field photomicrography along with DBH and ChAT immunostaining, to help delineate catecholaminergic and cholinergic medullary regions. To map H129-infected neurons and fibers, circles and lines were drawn in an Al layer over every eGFP-labeled structure. After the mapping, a merged maximum projection intensity image of the same section used to map, that included eGFP, DBH and ChAT immunostaining, was used to identify eGFP single-labeled neurons, eGFP/DBH or eGFP/ ChAT double-labeled, and eGFP/DBH/ChAT triple-labeled neurons. Cells and fibers representations were then superimposed onto the corresponding $\mathrm{AL}$ template, creating atlas-based maps of the DVC of PMV wall H129-injected rats.

\section{Statistics}

Body weight (BW) data are expressed as mean \pm SEM. Changes in BW between groups along survival times are expressed as percentage change in BW from the day of surgery. Statistically significant changes $(p<0.05)$ were detected by one-way ANOVA (JMP Pro 14 Software, SAS Institute Inc.).

\section{Results}

\section{The effects of $\mathrm{H} 129$ infections on BW}

All H129-infected animals remained asymptomatic at all survival times as assessed by coat condition, locomotion, and signs of general malaise. PMV wall-injected rats increased their mean BWs by $8.3 \% 120 \mathrm{~h}$ after surgery compared with their presurgery BWs (Table 2; $F_{(4,189)}=$ $\left.30.48, p=1.40178 \mathrm{E}^{-19}\right)$. Although PMV lumen and surface administered animals showed increased BWs during their survival period, these were not significant from their surgery day weights most likely because of the variance 
Table 2. Percentage change in BW from surgery

\begin{tabular}{|c|c|c|c|c|c|c|}
\hline Target & Preinjection BW (g) & $\begin{array}{l}\text { Survival times } \\
24 \mathrm{~h}\end{array}$ & $48 \mathrm{~h}$ & $72 \mathrm{~h}$ & $96 \mathrm{~h}$ & $120 \mathrm{~h}$ \\
\hline PMV lumen & $268.0 \pm 6.9$ & $-0.5 \pm 1.0$ & $0.9 \pm 0.9$ & $2.7 \pm 0.8$ & $5.8 \pm 0.5$ & $8.5 \pm 1.2$ \\
\hline LNG & $297.7 \pm 5.4$ & $-0.9 \pm 0.7$ & $-4.9 \pm 1.3^{*}$ & $-8.0 \pm 3.3^{\star}$ & & \\
\hline
\end{tabular}

Percentage of BW changes along survival times compared with the preinjection BW. Data of preinjection BW are expressed as the mean \pm SEM in grams (PMV wall $n=44$; PMV lumen $n=6$; PMV surface $n=5$; LNG $n=12$ ). Values of change of BW along the survival times are expressed as the mean \pm SEM in percentages. One-way ANOVA showed differences between survival times, PMV wall group ${ }^{*} p=1.40178 \mathrm{E}^{-19}$ and $\mathrm{LNG}$ group ${ }^{*} p=0.0018$ versus their own preinjection BW.

within the small group number. In contrast, the mean BWs of LNG-injected rats decreased by $8 \%$ compared with presurgery BW after $72 \mathrm{~h}$ (Table 2; $F_{(3,32)}=6.22, p=$ 0.0018).

\section{H129 brain infections, general observations}

The presence and extent of $\mathrm{H} 129$-infected cells in the DVC after PMV wall injections varied greatly between individual cases. These ranged from animals that had no discernable infections, animals with only one or two neurons, to those that had substantial infections. Nonetheless, the distribution of infected glial cells, neuronal soma, dendrites, and axons was virtually identical between all animals in the same experimental group. However, three PMV wall-injected animals did have $\mathrm{H} 129$ infection patterns that were completely different from all others, and so were excluded from further analyses. One of the five PMV surface-injected animals had infection in the brain, the pattern of which was identical to the PMV wall-injected animals. We attribute this infection to $\mathrm{H} 129$ infiltrating into the PMV wall, which in this animal was damaged by the microinjector during the surface application. No PMV lumen-injected animals had infections in the brain. Table 1 shows that the infection efficiency of PMV wall injections appeared to vary according to the targeted site, with those in the SMV wall (group 3) being more effective $(63 \%)$ than those proximal to the porta hepatis (group 1; $46 \%)$.

Although the PMV wall-injected animals had 96- and 120-h survival times, the large variation in infection intensities between animals precluded our ability to assess any time-dependent infection progression pattern. However, our LNG injections did provide some appreciation of how $\mathrm{H} 129$ infections progressed through connected brain regions. Ten from a total of twelve LNG-injected animals had eGFP-ir in the DVC. One animal from each of the 24and 72-h groups had no detectable eGFP-ir in the DVC. Figure 2 shows that the earliest evidence of infection was increased in eGFP-ir in what appeared to be astrocytes in the NTS, AP, and DMX after 24-h survival (Fig. 2A-C). As the infection progressed to $48 \mathrm{~h}$ (Fig. $2 D-G$ ), the numbers of eGFP-ir neurons increased in these same regions, but most notably in the AP. Astrocytes with eGFP-ir were still seen in some regions at this time (Fig. 2Ei, Fi).

By $72 \mathrm{~h}$ (Fig. $2 \mathrm{H}-J$ ), substantial numbers of eGFP-ir neurons were now evident in the NTS, AP, and DMX, although no 72-h animal appeared to be more heavily infected than the 48-h animal shown in Figure 2G. These results show that the time course for $\mathrm{H} 129$ infections varies from animal to animal even when the same target is injected. For example, the extent of infections in 48-h survival animals varied from scant (Fig. $2 D$ ) to substantial (Fig. 2G). These two animals were injected on the same day with the same volume and virus titer, and were perfused after the same survival time. This means that the correlation between the infection extent and survival time is not tight (also see Lo and Anderson, 2011).

\section{Comparing the distribution of $\mathrm{H} 129$-infected neurons after injections in the PMV wall or the LNG}

Figure $3 A$ shows that in PMV wall-injected animals the distribution of $\mathrm{H} 129$ infection after $120 \mathrm{~h}$ was restricted to the DMX with only very occasional infections seen in the NTS most of which were adjacent to its border with the DMX (see also Fig. 4).

Most identifiable H129-infected cells in LNG-injected rats with the shortest survival time (24 h) were glial cells in the NTS, although one neuron was evident in the DMX (Fig. $2 A-C$ ). As expected with the two longer survival times (48 and 72 h), LNG-injected animals had significantly more extensive neuronal infections in the DVC than in any PMV wall-injected animals.

Figure $3 B$ shows that after $48-h$ survival, LNG-injected animals display a distribution of $\mathrm{H} 129$-infected neurons in the DVC that is characteristic of vagal sensory inputs, the vast majority of which were found in the left lateral, commissural, and caudal NTS. The AP was also heavily infected. Furthermore, the A1/C1 catecholaminergic cell group in the left ventrolateral medulla (VLM) showed H129-infected neurons that co-occurred with DBH (Fig. $3 B$ ). At this DVC level (AL 69-70) in this particular animal no $\mathrm{H} 129$-infected neurons were evident in the DMX (Fig. $3 B$ ). However, Figure $2 D-G$ shows that $\mathrm{H} 129$-infected neurons were present at this and other levels of the DMX of all 48-h animals, including the animal shown in Figure 3B (Fig. 2E).

After 72 -h survival, Figure $3 \mathrm{C}$ shows that in addition to the infected regions seen in the 48-h LNG rats, H129 infection progressed to the right NTS and VLM, and to the left DMX, and was much heavier than in most animals surviving for $48 \mathrm{~h}$. We note that the extent of $\mathrm{H} 129$ infections did not always correspond to survival times. Thus, one 48-h animal (Fig. 2G) showed at least as extensive a degree of $\mathrm{H} 129$ infection as the 72-h animals (Fig. $2 \mathrm{H}-J$ ). 


\section{$24 \mathrm{~h}$}
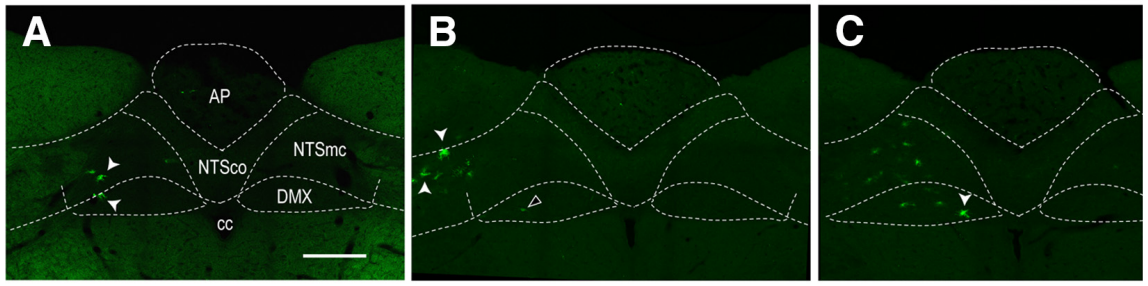

$48 \mathrm{~h}$
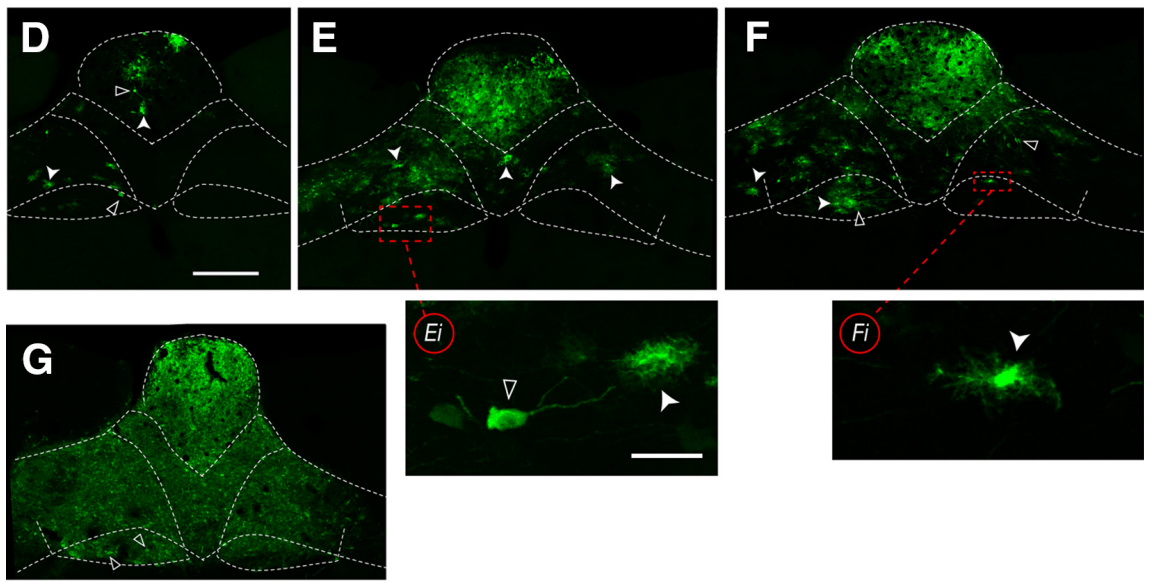

$72 \mathrm{~h}$
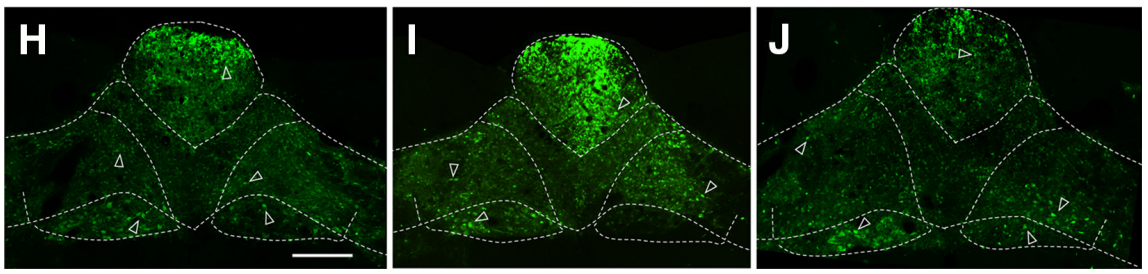

Figure 2. The distribution of $\mathrm{H} 129$ infections in the DVC after 24, 48, or $72 \mathrm{~h}$ survival times following H129 injections in the LNG. The dorsal medulla of rats $24 \mathrm{~h}(\boldsymbol{A}-\boldsymbol{C})$, $48 \mathrm{~h}(\boldsymbol{D}-\mathbf{G})$, or $72 \mathrm{~h}(\boldsymbol{H}-\boldsymbol{J})$ after H129 injections into the LNG. Each panel $(\boldsymbol{A}-\boldsymbol{J})$ corresponds to a different animal. Closed arrowheads show eGFP-ir in H129-infected astrocytes; open arrowheads show eGFP-ir in H129-infected neurons. 24h, Astrocytes are the first cells to be infected after H129 arrives into brain in LNG sensory neurons. A few cells are evident in the AP $(\boldsymbol{A}, \boldsymbol{B}), \mathrm{NTS}$, and DMX $(\boldsymbol{A}-\boldsymbol{C}) 24 \mathrm{~h}$ after LNG injections. One animal in this group had no apparent infection of any kind (data not shown). 48h, Infected neurons are apparent together with infected astrocytes $48 \mathrm{~h}$ after $\mathrm{H} 129$ injections. These cells are evident in the NTS and DMX of all four animals (D-G; and at higher magnification in Ei, Fi). Their numbers are highly variable between individuals despite the same survival times. Panel $\boldsymbol{E}$ shows the adjacent section from the 48 -h animal in Figure 3 . $72 \mathrm{~h}$, By $72 \mathrm{~h}$, large numbers of infected neurons are seen in the AP, NTS, and DMX, particularly the left DMX. Scale bars: $100 \mu \mathrm{m}(\boldsymbol{A}-\boldsymbol{J})$ and $50 \mu \mathrm{m}(\boldsymbol{E} \boldsymbol{i}$, Fi). AP, area postrema; cc, central canal; DMX, dorsal motor nucleus of the vagus nerve; NTSco, commissural part of the nucleus of the solitary tract; NTSmc, caudal subzone of the medial part of the NTS.

\section{Distribution H129 in the DVC of PMV wall-injected rats}

Figure 4 shows the locations of H129-infected neurons as well as their co-occurrence with catecholaminergic and/or cholinergic markers in the DVC after injections into the PMV wall. We found that virtually all $\mathrm{H} 129$-infected neurons were restricted to the DMX with only occasional infected cell bodies in the part of the NTS immediately dorsal to its border with the DMX (identified using the locations of ChAT-ir neurons). H129-infected neurons were located across the complete rostrocaudal extent of the DMX, including regions in the cervical spinal cord (Fig.
$5 B)$. They were most abundant in the mid-levels of the DVC at AL $67-70$ and accounted for $\sim 70 \%$ of all $\mathrm{H} 129$-infected DVC neurons (Fig. 4G,I-K). The numbers of H129-infected neurons were asymmetric with $\sim 50 \%$ more neurons in the left DMX compared with the right (Fig. 4L). Although the numbers of neurons containing eGFP-ir varied greatly between PMV wall-injected animals, neuronal locations in all animals were consistent with those shown in Figure 4. Please note that we present evidence later in Discussion for excluding the delayed retrograde transport of $\mathrm{H} 129$ as a contributor to the DMX labeling we describe here. 

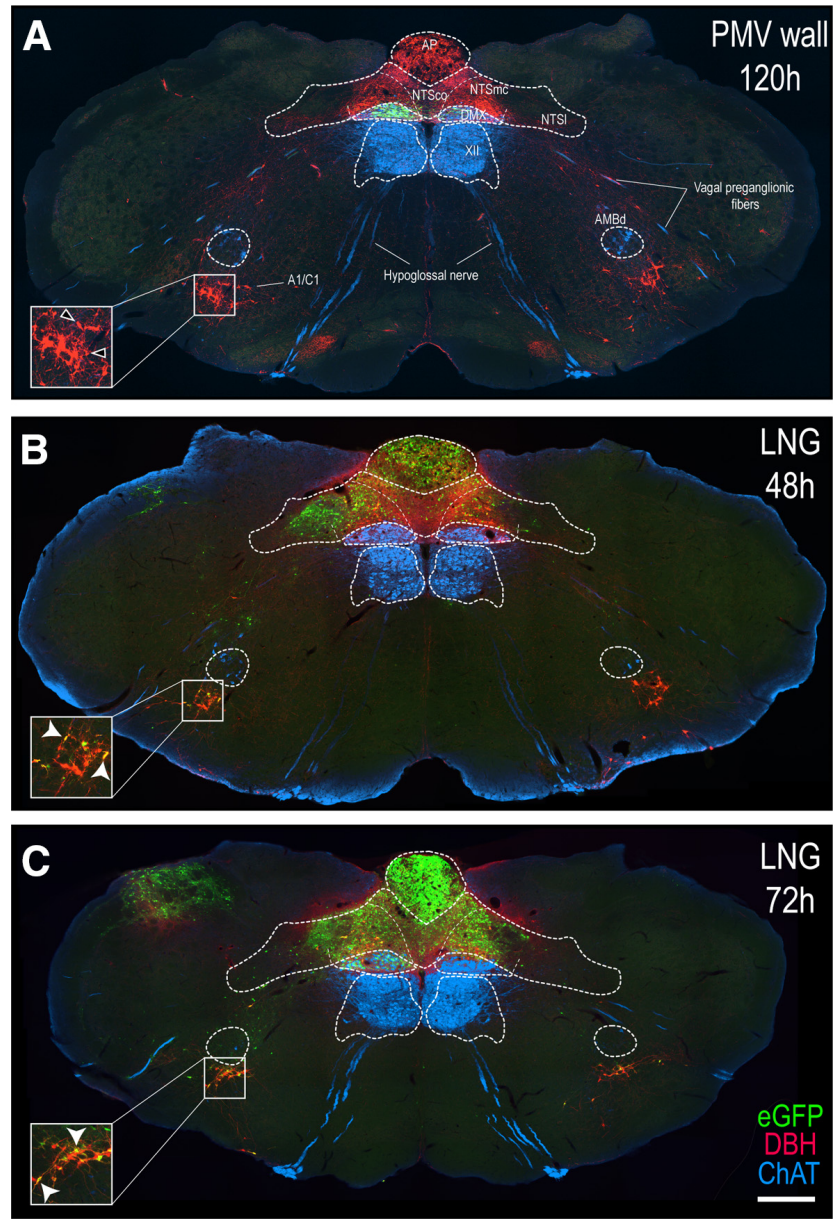

Figure 3. Differential distribution of $\mathrm{H} 129$ infection in the hindbrain of PMV wall-injected and LNG-injected rats. Epifluorescence photomicrographs of PMV wall-injected animals after 120-h survival $(\boldsymbol{A})$, and LNG-injected rats with a survival times of $48 \mathrm{~h}(\boldsymbol{B})$ or $72 \mathrm{~h}(\boldsymbol{C})$, indicating $\mathrm{H} 129$ infection (eGFP, green channel), catecholaminergic (DBH, red channel), and cholinergic (ChAT, blue channel) neurons. Note that in PMV wall injection $(\boldsymbol{A})$, eGFP-ir labeling is restricted to the DMX, whereas in LNG injections, H129 infection starts at the AP and NTS $(\boldsymbol{B})$, and it progresses until it reaches also the DMX $(\boldsymbol{C})$. Insets show higher magnification images of $\mathrm{A} 1 / \mathrm{C} 1$ cell group indicated by the white boxes. Single DBH-labeled neurons are shown with the open arrowheads, and double-labeled eGFP + DBH neurons are shown with white arrowheads. Scale bar: $200 \mu \mathrm{m}$. A1/C1, noradrenergic/adrenergic cell group $\mathrm{A} 1$; $\mathrm{AMBd}$, dorsal division of the ambiguus nucleus; AP, area postrema; DMX, dorsal motor nucleus of the vagus nerve; NTS, nucleus of the solitary tract; NTSco, commissural part of the NTS; NTSI, lateral part of the NTS; NTSmc, caudal subzone of the medial part of the NTS; XII, hypoglossal nucleus.

Dendrites of H129-infected neurons in the DMX often extended appreciable distances beyond its border. At levels containing the AP (AL 69-73), these dendrites extended laterally across the midline into the contralateral DMX, or dorsally into the commissural and medial-caudal parts of the NTS toward, and in some cases closely approached the AP (Figs. 4J-O, 5A, 6A,A1).

Preganglionic DMX neurons are topographically organized in columns that control different gastrointestinal organs (Fox and Powley, 1985). However, despite H129 infections being distributed along the entire rostrocaudal extent of the DMX (Figs. 4, 5), including its extension into the cervical spinal cord (Dennison et al., 1981), we were unable to discern any notable columnar organization to PMV H129 infections.

\section{Co-occurrence of $\mathrm{H} 129$ with cholinergic and catecholaminergic neurons in the DVC}

Consistent with the vast majority of DMX neurons being cholinergic, we found that in the two most extensively labeled cases $93 \%$ of all H129-infected neurons in the DMX also contained ChAT (Fig. 4D,H,L,P1-P4). However, 6\% of H129-infected ChAT neurons also contained DBH. These triple-labeled neurons were in the rostral DMX (AL 63-66) in a region that was closely located to noradrenergic A2 neurons (Fig. 4C-F). In more medial and caudal parts of the DMX (AL 67-73), the majority of H129-infected neurons co-occurred with ChAT $(96 \%)$ but not DBH (Fig. 4G-P). We also found eGFP-ir in some ChATcontaining axons that appeared to originate from cholinergic DMX neurons indicating $\mathrm{H} 129$ infections in their output axons (Fig. 6B,B1-B4). We did not find eGFP-ir in any $\mathrm{DBH}$-containing axons.

\section{Spinal and vagal sensory neurons both contribute to H129 PMV wall infections in the brain}

We found H129-infected neurons and fibers in the thoracic DRGs, and in both nodose ganglia of PMV wall-injected animals (Fig. $7 A-C$ ) confirming that both spinal and vagal sensory routes were taken by $\mathrm{H} 129$ to reach the DVC. ChAT-ir axons seen in the sections containing the DRG and nodose ganglia were confined to the ventral roots of spinal motor nerves that are located adjacent to the DRGs (Fig. 7D), and to the vagal motor nerves in the nodose ganglia that run parallel to but are separate from the vagal sensory nerves (Fig. 7E). No eGFP-ir was evident in any of these axons.

H129-infected vagal sensory fibers co-occurred with the primary sensory nerve marker IB4 in the medullary dorsal root entry zone of vagal sensory fibers of PMV wall-injected rats. eGFP-ir fibers of PMV wall-injected animals were evident at the dorsolateral root entry zone of vagus nerve and along the intramedullary path to the DVC co-occurring with the vagal sensory marker IB4 (Fig. 8A, A1-A3). These H129-infected vagal sensory axons were only seen at the left entry zone of the ventral root.

\section{Vagal sensory appositions to DMX neurons and their dendrites in the NTS}

Figure 9 shows that eGFP, IB4, and Synl-ir were found in the medial and commissural NTS, and in the DMX. Thus, by using Synl to delineate axon terminals (Fig. 9B1,C1) we were able to create white masks that identified those structures where Synl co-occurred with eGFP-ir and/or IB4 (Fig. 9B2$B 4, C 2-C 4)$. Not only did we find vagal sensory axons from the PMV wall terminating in the medial and commissural NTS but also in the DMX (Fig. 9A-C). Additionally, we found more eGFP-ir and Synl appositions with dendrites and cell bodies 

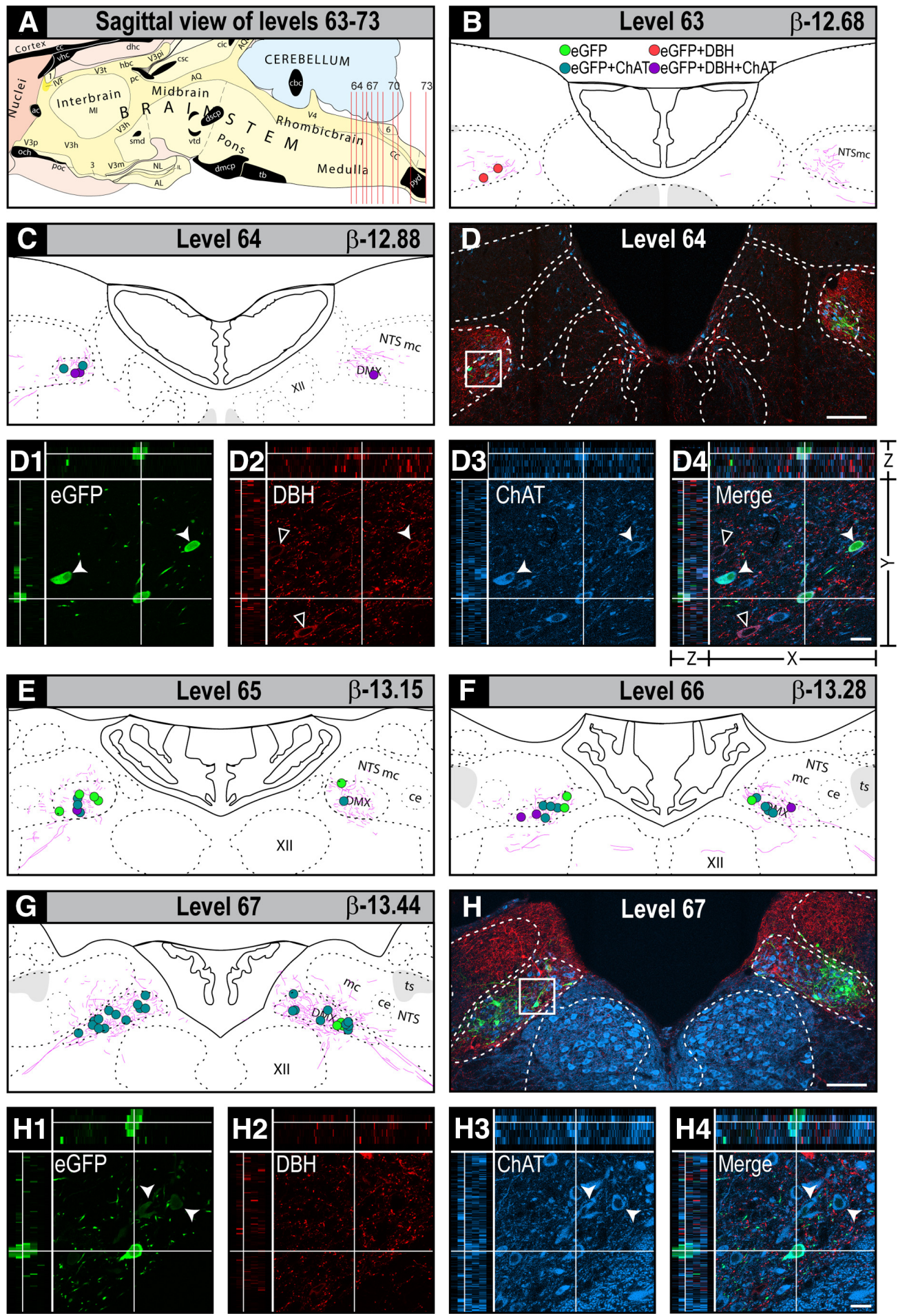

Figure 4. The locations of H129-infected neurons and their co-occurrence with catecholaminergic and cholinergic neurons in the DVC of PMV wall-injected rats. Locations eGFP-ir neurons in the DVC after H129 injections in the walls of the PMV. Locations and co-occurrence results are presented in two ways. First plotted onto maps of levels 63-73 from the Swanson Rat Brain Atlas (Swanson, 2018). Panel $\boldsymbol{A}$ shows a sagittal view of the caudal brainstem indicating rat brain AL 63-73 that cover the entire dorsal DVC. Individual levels are shown in the following panels: (B) 63, (C) 64, (E) 65, (F) 66, (G) 67, (I) 68, (J) 69, (K) 70, (M) 71, (N) 72, and (O) 73. The maps also show locations of neurons where eGFP-ir co-occurred in neurons containing DBH-ir and/or ChAT-ir. Maps are plotted as composites to represent the locations of H129-infected neurons at each AL. They derive from all infected animals. The map color codes are shown in $\boldsymbol{B}$ and are as follows: green dots, eGFP-ir somata; red dots, double-labeled eGFP-ir + DBH somata; cyan dots, double-labeled eGFP + ChAT somata; purple dots, triple-labeled eGFP + DBH + ChAT somata; pink lines, eGFP-ir neuronal processes. Each dot indicates one neuron. Second, confocal photomicrographs of sections of locations from four selected rat brain $A L(D) 64,(\boldsymbol{H}) 67,(\boldsymbol{L}) 70$, and $(\boldsymbol{P})$ ) 73. These same panels also show higher magnification confocal maximum projections of selected DVC regions to illustrate co-occurrence. The white squares show the sampled region observed in panels $\boldsymbol{D}, \boldsymbol{H}, \boldsymbol{L}$, and $\boldsymbol{P}$. They are labeled 1-4 in each case. Green channel, eGFP; red channel, DBH; 

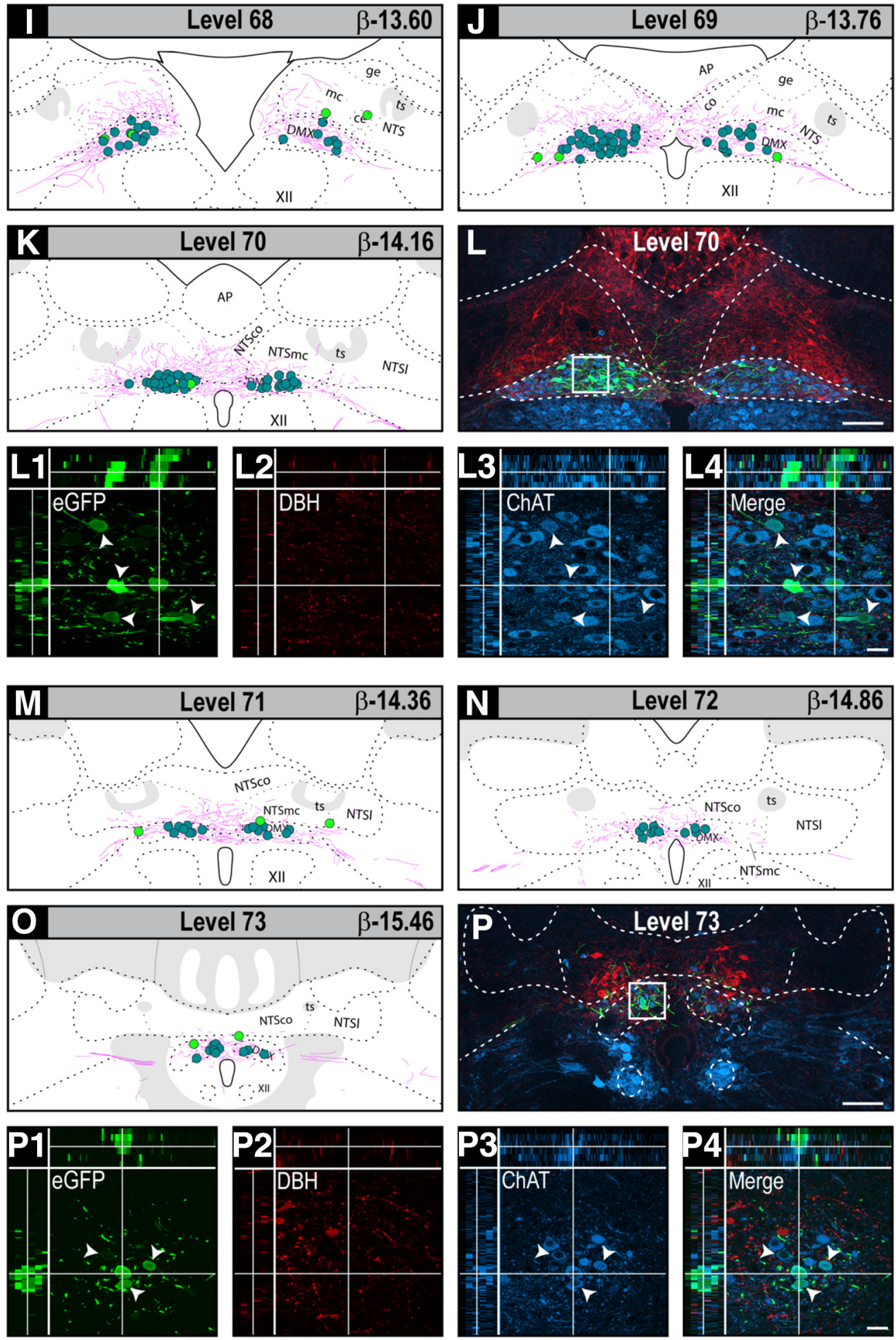

Figure 4. (Continued) blue channel, ChAT. Panels 1-4 in $\boldsymbol{D}, \boldsymbol{H}, \boldsymbol{L}, \boldsymbol{P}$ also show the three-plane orthogonal view obtained from their confocal Z-stacks. Each panel 1 shows structures labeled for eGFP (D1, H1, L1, P1); panel 2 shows structures labeled for DBH (D2, H2, L2, P2); panel 3 shows structures labeled for ChAT (D3, H3, $\mathbf{3} \mathbf{3}, \boldsymbol{P} \mathbf{3})$; and panel 4 the respective merged images, where single labeled structures are green, red, or blue and co-occurring structures in cyan, yellow, or purple $(\boldsymbol{D} \mathbf{4}, \mathbf{H 4}, \mathbf{L 4}, \mathbf{P 4})$. Double-labeled or triple-labeled neurons that contain eGFP are shown with the white arrowheads, and double-labeled DBH + ChAT neurons are shown with open arrowheads. The arrangement of the $x-, y$-, and $z$-axes is shown on panel $\boldsymbol{D} 4$, and the horizontal and vertical white lines in panels 1-4 of $\boldsymbol{D}, \boldsymbol{H}, \boldsymbol{L}, \boldsymbol{P}$ target a representative double or triple-labeled structures in the $x$-, $y$-, and $z$-axes. Scale bars: 100 $\mu \mathrm{m}(\boldsymbol{D}, \boldsymbol{H}, \boldsymbol{L}, \boldsymbol{P})$ and $20 \mu \mathrm{m}$ (panels 1-4 of $\boldsymbol{D}, \boldsymbol{H}, \boldsymbol{L}, \boldsymbol{P})$. AP, area postrema; DMX, dorsal motor nucleus of the vagus nerve; NTS, nucleus of the solitary tract; NTSce, central part of the NTS; NTSco, commissural part of the NTS; NTSge, gelatinous part of the NTS; NTSI, lateral part of the NTS; NTSmc, caudal subzone of the medial part of the NTS; ts, solitary tract; XII, hypoglossal nucleus. 

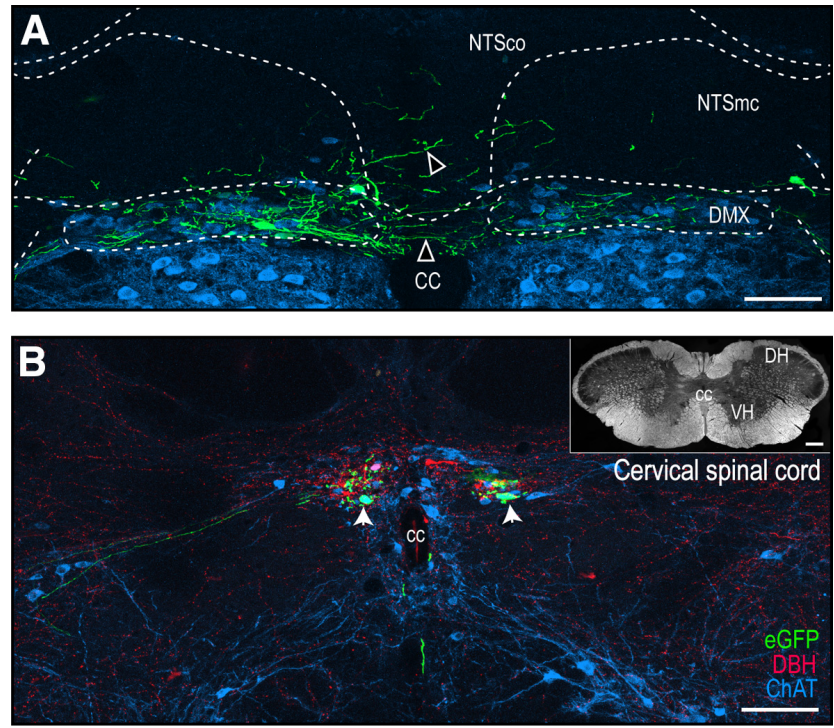

Figure 5. H129-infected neurons in the DVC and cervical spinal cord. Confocal maximum projections of a representative section of the DVC corresponding to Swanson rat brain AL 70 (Swanson, 2018; $\boldsymbol{A}$ ) and of eGFP-labeled structures at a representative cervical spinal cord section $(\boldsymbol{B})$. Open arrowheads show eGFP-labeled neurons that cross the midline or extend dorsally from the DMX to the NTS $(\boldsymbol{A})$. White arrowheads indicate double-labeled eGFP + ChAT somata. Green channel, eGFP; red channel, DBH; blue channel, ChAT. Dark-field photomicrograph of the complete cervical spinal cord section is shown in $\boldsymbol{B}$. Scale bars: $100 \mu \mathrm{m}(\boldsymbol{A}, \boldsymbol{B})$ and $200 \mu \mathrm{m}$ ( $\boldsymbol{B}$, inset). $\mathrm{Cc}$, central canal; DH, dorsal horn; DMX, dorsal motor nucleus of the vagus nerve; NTSco, commissural part of the NTS; NTSmc, caudal subzone of the medial part of the NTS; $\mathrm{VH}$, ventral horn.

in both the commissural NTS and the DMX (Fig. 9B2,C2) than those containing all three labels (eGFP, IB4, and Synl) in the same regions (Fig. 9B3,C3and B4,C4). However, the existence of triple-labeled terminal appositions clearly showed vagal sensory neurons from the PMV wall terminate on DMX dendrites in the commissural NTS and DMX, as well as on DMX somata.

\section{Discussion}

Our principal finding is that chemosensory information from the PMV wall is conveyed by vagal and spinal routes to a group of neurons located along the entire rostrocaudal extent of the DMX, but predominantly on its left side. Although we found evidence of $\mathrm{H} 129$-infected spinal and particularly vagal (i.e., IB4-containing) terminal appositions in the NTS, the dearth of H129-infected NTS neuronal somata supports a route into the DMX that does not include NTS neurons. Moreover, we found evidence of H129-infected vagal sensory terminal appositions on dendrites and neuronal somata in the DMX itself, as well as on DMX dendrites that extend into the NTS. Before discussing the anatomical and functional aspects of our findings, we first consider the technical constraints of our methods.

\section{Technical considerations}

$\mathrm{H} 129$ has been used in different mammals to map neuronal networks that receive sensory information from the nodose ganglia (Han et al., 2018), visual system (Archin and Atherton, 2002), stomach (Rinaman and Schwartz, 2004; Horn et al., 2014), white and brown adipose tissue (Song et al., 2009; Ryu et al., 2017), and airway pathways (McGovern et al., 2012, 2015). These studies used different survival times and reported infections of variable severity and prevalence that are dictated by the different injection sites. Furthermore, Lo and Anderson (2011) reported that, depending on their injection sites, $20 \%$ to almost $50 \%$ of their $\mathrm{H} 129$-injected animals never developed any detectable sign of infection. Although most of our animals developed $\mathrm{H} 129$ infections in the DVC, their intensity and abundance, but not their locations, was highly variable among animals, observations that are consistent with previous studies.

Although $\mathrm{H} 129$ is transported primarily in an anterograde direction, it does have a delayed and less efficient nontranssynaptic retrograde component when injected peripherally. Importantly, however, this is limited to the primary neurons of the sensory chain (Archin and Atherton, 2002; Rinaman and Schwartz, 2004; McGovern et al., 2012; Wojaczynski et al., 2015). When considering evidence of retrograde transport, we believe that the following sets of results exclude the possibility that the monosynaptic retrograde component of $\mathrm{H} 129$ transport accounts for any $\mathrm{H} 129$ infections in the DVC.

First, while the HPV wall receives some sympathetic motor innervation, any postganglionic parasympathetic motor innervation is limited to occasional cholinergic endings in the HPV wall after it enters the liver in the porta hepatis (Reilly et al., 1978; Berthoud et al., 1992; Akiyoshi et al., 1998; Schäfer et al., 1998). Most importantly, retrograde transport of $\mathrm{H} 129$ does not proceed beyond firstorder neurons (i.e., it is only monosynaptic). Because DMX neurons are preganglionic parasympathetic neurons, and therefore do not innervate the final target organ (in this case the PMV wall) they cannot be infected by retrograde transmission. However, we do note that the locations of parasympathetic ganglia within the liver are unknown (Berthoud, 2004) meaning that we cannot know how close these may be to the porta hepatis. All our injections were placed in the HPV wall outside the liver (Fig. 1) to avoid those parts of the porta hepatis that may contain occasional parasympathetic motor fibers. Furthermore, those injections that were the closest to the porta hepatis (Fig. 1, group 1), and therefore the closest to possible vagal motor endings, were the least effective at generating brain infections (Table 1), group 3 animals that were injected in the SMV wall, and so the furthest from the porta hepatis, were the most successful. Second, we used two controls to account for any infection that may have derived from the spread of $\mathrm{H} 129$ away from the targeted injection sites: H129 injections into the PMV lumen, and application of $\mathrm{H} 129$ onto the PMV surface. Only one PMV surface application generated any labeled neurons in the brain, but this animal had an identical infection 

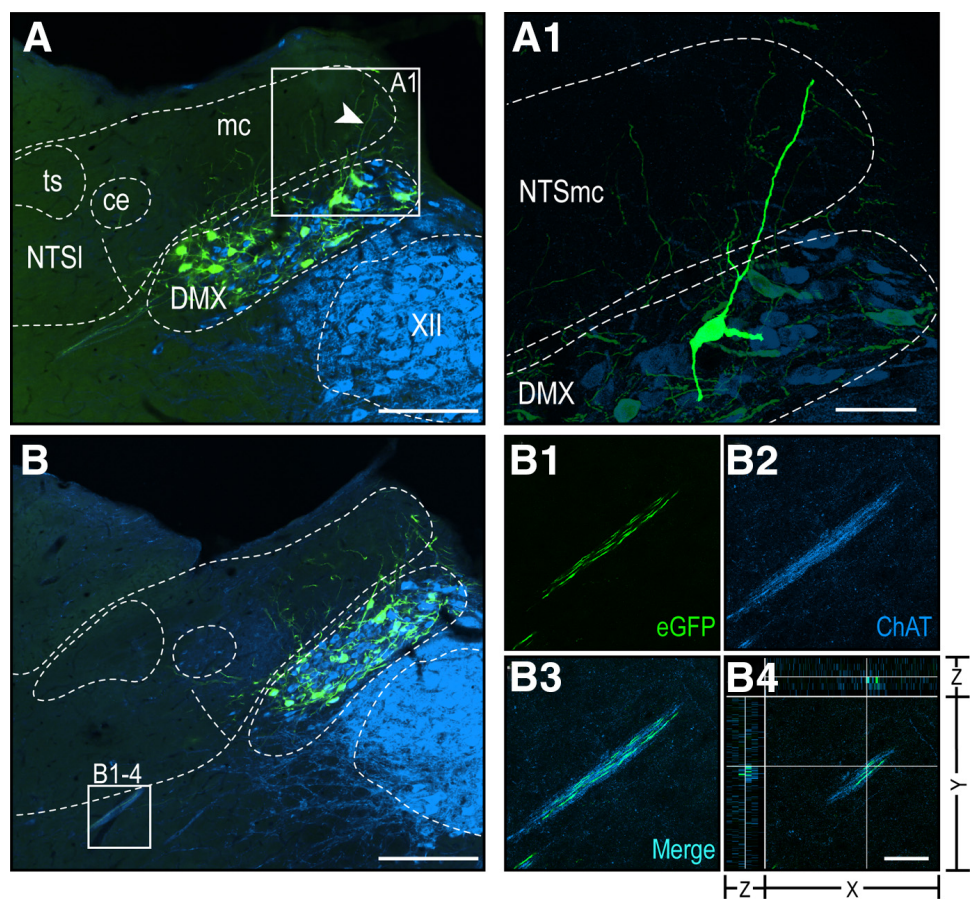

Figure 6. Co-occurrence of $\mathrm{H} 129$ with ChAT in DMX neurons of PMV wall-injected rats. Epifluorescence photomicrographs showing dendrites $(\boldsymbol{A})$ or axons $(\boldsymbol{B})$ of the DVC corresponding to Swanson rat brain AL 67 (Swanson, 2018). Confocal maximum projection of the DVC showing a dendrite from a DMX neuron (white arrowhead in $\boldsymbol{A}$, which is also shown at higher magnification in $\boldsymbol{A 1}$ ), that extends dorsally to NTSmc territory. Confocal maximum projections of eGFP-labeled (B1) and ChAT-labeled (B2) axons. Panel B3 shows the merged image where single labeled structures are in green or blue, and co-occurring structures in cyan. Three plane orthogonal view is shown in $\mathbf{B} 4$ indicating the co-occurrence of eGFP and ChAT. The arrangement of the $x-, y-$, and $z$-axes is shown on panel B4. Green channel, eGFP; blue channel, ChAT. Scale bars: $200 \mu \mathrm{m}(\boldsymbol{A}, \boldsymbol{B}), 50 \mu \mathrm{m}(\boldsymbol{A 1}), 40 \mu \mathrm{m}(\boldsymbol{B} 1-\boldsymbol{B} 4)$. DMX, dorsal motor nucleus of the vagus nerve; NTSce, central part of the NTS; NTSI, lateral part of the NTS; NTSmc, caudal subzone of the medial part of the NTS; ts, solitary tract; XII, hypoglossal nucleus.

pattern to PMV wall-injected animals. Figure 1 shows that abdominal white adipose tissue (WAT) is the most abundant tissue adjacent to the PMV. But given that WAT is not innervated by parasympathetic motor neurons
(Bartness et al., 2014; Ryu et al., 2017) inadvertent spread of H129 into adjacent WAT cannot provide a source of retrograde labeling in the DMX. Third, in those animals that had significant infections in the DVC after H129 PMV wall-


Figure 7. H129-infected sensory neurons in nodose and DRGs of PMV wall-injected rats. Confocal photomicrographs of DRG (A), LNG $(\boldsymbol{B})$, and right nodose ganglion (RNG; $\boldsymbol{C}$ ) showing sensory neurons labeled with eGFP. Panels $\boldsymbol{D}, \boldsymbol{E}$ show that eGFP-labeled neurons (green channel) in the DRG $(\boldsymbol{D})$ and LNG $(\boldsymbol{E})$ are in completely separate locations to the cholinergic (ChAT, red channel) motor axons. Scale bars: $200 \mu \mathrm{m}(\boldsymbol{A}-\boldsymbol{D})$ and $300 \mu \mathrm{m}(\boldsymbol{E})$. 




Figure 8. Vagal sensory axons in PMV wall-injected rats. Confocal maximum projection showing H129-infected axons (eGFP, green channel) and the primary vagal sensory neuronal marker IB4 (red channel). The intramedullary path taken by vagal sensory axons to reach their targets in the DVC is clearly evident (white arrows). Low magnification of dark-field photomicrograph (panel $\boldsymbol{A}$, inset; Swanson rat brain AL 62 (Swanson, 2018) shows the pathway followed by the left sensory vagus nerve. Panels $\boldsymbol{A}$ 1-A3 show higher magnification images of the regions indicated by the white boxes in panel $\boldsymbol{A}$. Co-occurring fibers are seen in yellow and are indicated by the white arrowheads. Scale bars: $100 \mu \mathrm{m}(\boldsymbol{A}), 40 \mu \mathrm{m}(\boldsymbol{A} 1-\boldsymbol{A 3})$, and $200 \mu \mathrm{m}$ (A, inset). icp, inferior cerebellar peduncle; NTS, nucleus of the solitary tract; sptV, spinal tract of the trigeminal nerve.

injections we found abundant eGFP-ir in spinal neuronal somata and fibers in the DRG, and vagal neuronal somata and fibers in nodose ganglia (Fig. 7). Fourth, given that vagal preganglionic but not sensory neurons are cholinergic (Barber et al., 1984; Schäfer et al., 1998) we could not find any co-occurrence of ChAT and eGFP-ir in vagal preganglionic axons that are located adjacent to vagal sensory elements in the nodose ganglia (Fig. 7). Cholinergic spinal motor axons run in the ventral roots that are located adjacent to the DRGs (Bellier and Kimura, 2007). Again, we found no co-occurrence of eGFP-ir and ChAT-ir in these neurons. This is entirely expected given that these axons target the skeletal trunk muscles, which are clearly some distance from the PMV wall. Fifth, the co-occurrence of eGFP-ir in IB4-identified vagal sensory axons in the dorsolateral medulla (Fig. 8). Finally, the co-occurrence of eGFP-ir in Synl-identified terminal appositions in the NTS and DMX and importantly, the co-occurrence of eGFP-ir and Synl with the vagal sensory marker IB4 (Fig. 9). We believe that these findings collectively support a transynaptic anterograde-only direction of $\mathrm{H} 129$ transport from sensory endings in the PMV wall to axonal terminals in the NTS and DMX.

\section{Anatomical aspects}

\section{General observations}

The PMV wall is innervated by vagal and spinal sensory endings (Barja et al., 1983; Barja and Mathison, 1984; Berthoud et al., 1992; Akiyoshi et al., 1998; Fujita et al., 2007; Bohland et al., 2014; Mizuno and Ueno, 2017). But given the very limited information about the central targets of PMV wall sensory inputs, we used H129 infections from a time-series of LNG-injected animals to help us determine differences between the distribution pattern of sensory inputs from the PMV wall into medullary regions and that from a wider population of vagal sensory inputs. We found that unlike PMV wall H129 injections, where all DMX infections occurred with very few or no NTS infections (Fig. 2A), LNG H129 injections always infected the NTS (Figs. 2B,C, 3). Furthermore, DMX infections originating from these LNG H129 injections never occurred without the presence of infected NTS neurons, results that are consistent with those of Han et al. (2018), which also demonstrates consistency between rats and mice. These observations are also consistent with previous reports describing the DVC targets of vagal sensory nerves (Kalia and Mesulam, 1980; Kalia and Sullivan, 1982; Rogers and Hermann, 1983; Neuhuber and Sandoz, 1986; Han et al., 2018; Kim et al., 2020).

\section{Vagal sensory nerve projections from the PMV wall to the DVC}

The majority of vagal sensory nerves from the PMV wall travel in its common hepatic branch, and from there into the left cervical vagus nerve. However, the celiac branch and thereafter the right cervical vagus apparently does provide a minor contribution (Berthoud and Neuhuber, 2000; Berthoud, 2004). Consistent with this organization we found $\mathrm{H} 129$-infected neurons in the LNG of all animals that had significant infections in the DVC (Fig. 7). Furthermore, $\mathrm{H} 129$-infected vagal fibers were seen at the left, but not the right, root entry zone into the dorsolateral medulla (Fig. 8), suggesting that the left vagus sensory nerve innervates the PMV wall more prominently than the 

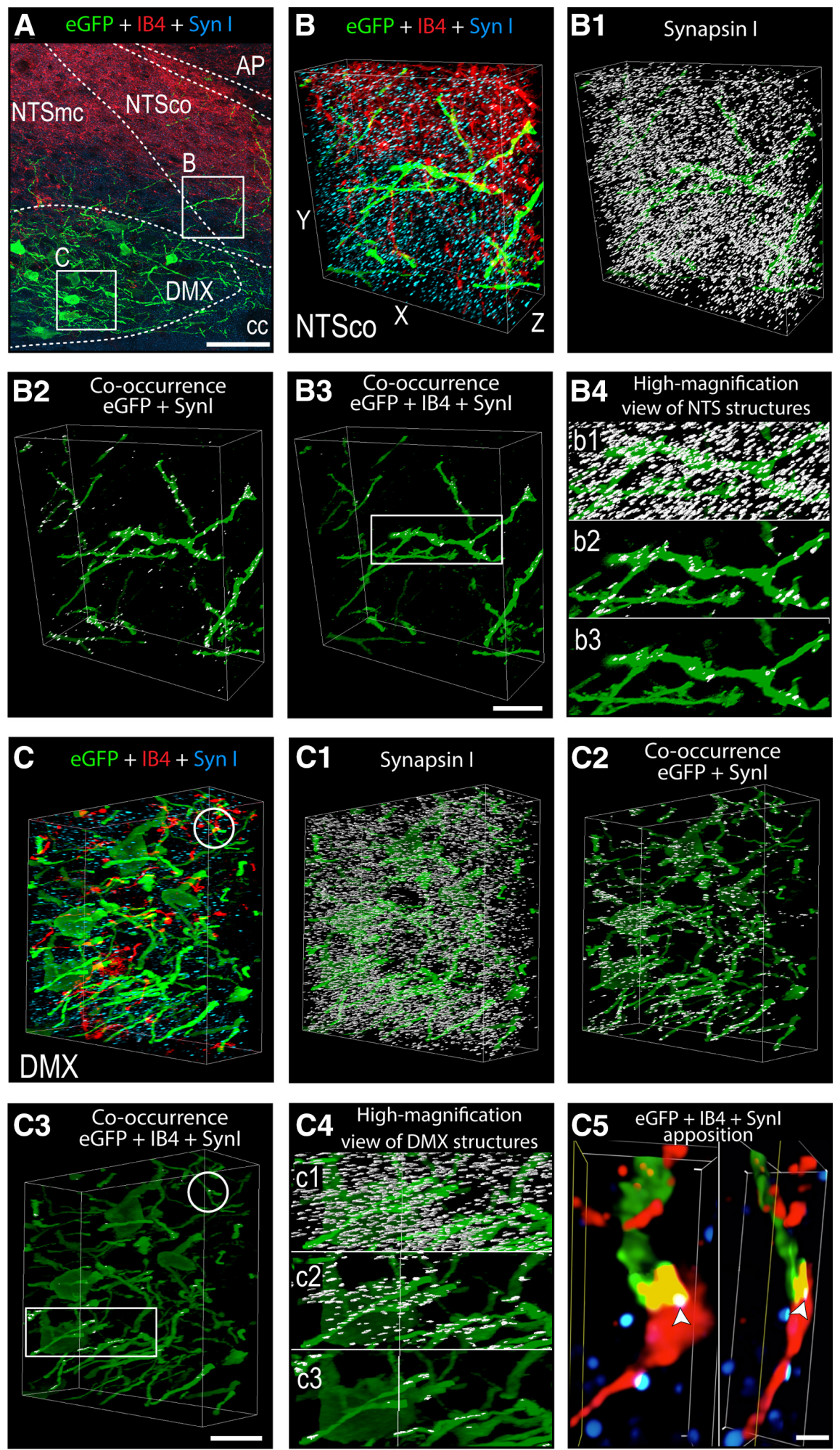

Figure 9. Vagal sensory appositions with H129-infected structures in the DVC of PMV wall-injected animals. Confocal maximum projection $(\boldsymbol{A})$ of eGFP (green channel), IB4 (red channel), and Synl (blue channel) labeling. 3D confocal reconstructions of 123 layers of a 30- $\mu \mathrm{m}$ Z-stack obtained from regions of the NTSco $(\boldsymbol{B})$ and the DMX $(\boldsymbol{C})$ indicated by the white boxes in $\boldsymbol{A}$ showing eGFP-labeled, IB4-labeled, and Synl-labeled structures $(\boldsymbol{B}, \boldsymbol{C})$. 3D confocal reconstruction of eGFP signal (green) and Synl (white mask; $\boldsymbol{B} 1$, C1), and of eGFP signal and the co-occurrence of double-labeled and triple-labeled structures in the NTSco (B2, B3) and the DMX (C2, C3). High-magnification view of B1-B3 NTS (B4) and C1-C3 DMX (C4) structures depicted in the white rectangle in B3, C3. Panel C5 shows a 3D confocal image of a vagal apposition (IB4 + Synl) to a H129-infected structure (eGFP) indicated by the white circles in $\mathbf{C}, \mathbf{C 3}$, derived from a 98 layer of a 13- $\mu \mathrm{m}$ Z-stack. The location where the three markers co-occur is white and indicated 
continued

by white arrowheads. The arrangement of the $x-, y$-, and $z$-axes is shown on panel $\boldsymbol{B}$. Scale bars: $20 \mu \mathrm{m}(\boldsymbol{A}, \boldsymbol{B} 3, \boldsymbol{C} 3)$ and $1 \mu \mathrm{m}(\mathbf{C} 5)$. $\mathrm{AP}$, area postrema; cc, central canal; DMX, dorsal motor nucleus of the vagus nerve; NTS, nucleus of the solitary tract; NTSco, commissural part of the NTS; NTSmc, caudal subzone of the medial part of the NTS.

right. Although we also found infections in the right nodose ganglion (Fig. 7), we cannot comment on whether these originated from the celiac branch of the vagus nerve or whether they traversed from the left to the right vagus via the thoracic communicating branch, which provides crossover access of sensory axons from one vagus nerve to the other (Sauter et al., 1983).

Vagal sensory axons terminate in the gelatinous, medial, and commissural parts of the NTS, as well as in the DMX (Kalia and Mesulam, 1980; Kalia and Sullivan, 1982; Rogers and Hermann, 1983; Neuhuber and Sandoz, 1986; Kim et al., 2020). We find the vast majority of eGFPcontaining neurons in the DMX co-occurs with ChAT, along with terminal appositions containing eGFP, Synl, and IB4 in the DMX (Fig. 9). These findings are consistent with a direct PMV wall vagal sensory termination onto these preganglionic parasympathetic neurons (Fig. 10A). We also find eGFP-containing terminal appositions in the medial and commissural NTS (Fig. 9). However, there are very few H129-containing neuronal somata in the NTS (Figs. 3-5), showing clearly that the main targets of sensory information from the PMV wall are neurons in the DMX not the NTS (Fig. 10A). In this way, vagal sensory neurons from the PMV wall must form a subset of those in the LNG that does not terminate on NTS neurons (Figs. 2, 3,10 ), thereby indicating a previously underappreciated degree of heterogeneity in the brain targets of vagal sensory neurons.

Direct PMV wall-vagal sensory projections to DMX neurons are most easily explained by the presence of eGFPcontaining terminal appositions with DMX somata and their dendrites in the DMX, as well as with dendrites of DMX neurons that extend dorsally into the NTS. Importantly, we find many H129-infected DMX dendrites that extend dorsally into the commissural and medialcaudal subregions of the NTS. Given that the vagal common hepatic branch has sensory nerves that originate in the gastrointestinal tract via its gastroduodenal branch (Berthoud et al., 1992), it seems likely that the gelatinous NTS receives gastric sensory terminals, whereas the medial and commissural NTS is the terminal zone for the majority of PMV wall vagal sensory nerves. Two sets of
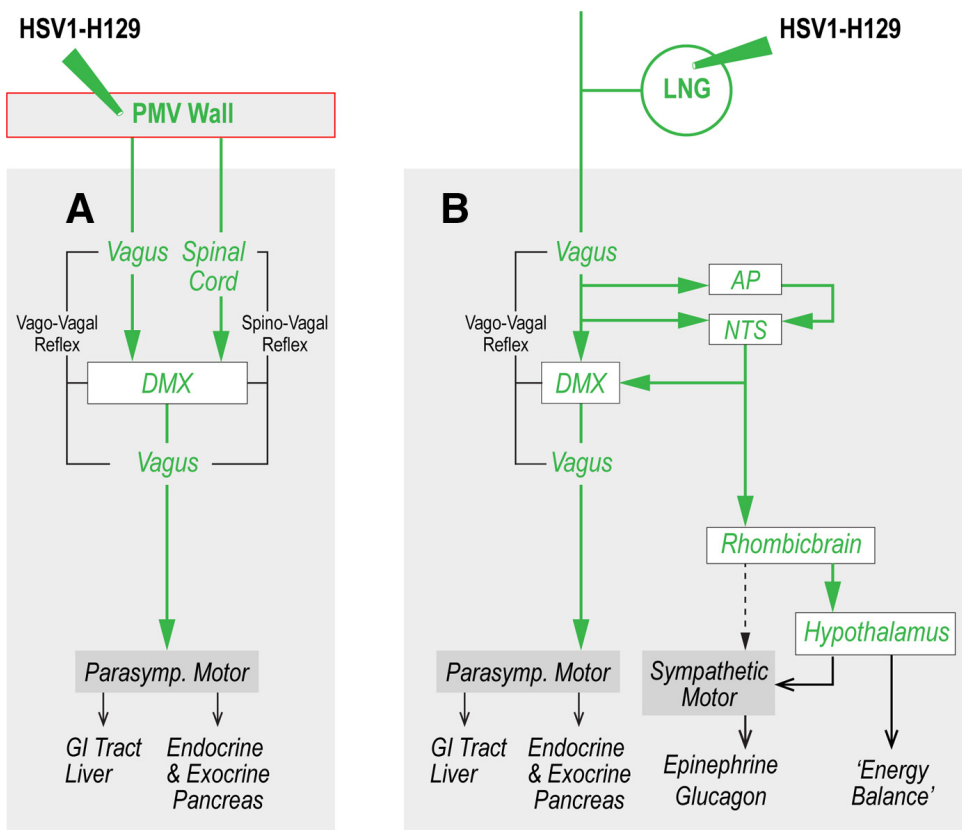

Figure 10. Schematic diagram illustrating the different brain targets of chemosensory information from the wall of the PMV and viscerosensory information conveyed by neurons in the LNG. H129 injections in the PMV wall result in the infection of two neuronal groups in the medulla. These two groups therefore receive chemosensory information from the PMV wall. The first one $(\boldsymbol{A})$ comprises preganglionic parasympathetic neurons located in the DMX that receives both vagal and spinal sensory inputs thereby enabling vago-vagal and spino-vagal parasympathetic reflexes. In turn, these reflexes control gastrointestinal tract, hepatic, and pancreatic function. LNG injections $(\boldsymbol{B})$ show that at least two subsets of vagal sensory inputs may exist: those that terminate in the NTS and AP, consistent with classic sensory systems; and those that derive from PMV wall that terminate exclusively in the DMX. The first group enables ascending projections to integrate vagal sensory information more widely in the brain (also see Krieger et al., 2018), while the second controls parasympathetic vago-vagal reflexes. AP, area postrema; DMX, dorsal motor nucleus of the vagus nerve; HSV1-H129, herpes simplex virus-1 strain H129; LNG, left nodose ganglion; NTS, nucleus of the solitary tract; PMV, hepatic portal and superior mesenteric veins. 
results are consistent with the notion that the NTS is the location where vagal sensory terminals can appose the dendrites of DMX neurons. First, DMX neurons that innervate the gastrointestinal tract have dendrites that extend into the gelatinous part of the NTS where they receive synaptic input from vagal sensory terminals (Shapiro and Miselis, 1985; Rinaman et al., 1989). Second, we find appositions containing eGFP, Synl, and IB4 in the commissural NTS decorating the dendrites of $\mathrm{H} 129$-infected DMX neurons (Fig. 9).

\section{Spinal sensory nerve projections from the PMV wall to the DVC}

Three sets of results evince that spinal sensory inputs play an important role in conveying PMV wall chemosensory information into the medulla. First, the ability of visceral stimuli to excite DMX neurons by way of direct spinal sensory inputs is blocked by lesioning DRGs (T6T12; Renehan et al., 1995). Second, those PMV glucosensors important for detecting hypoglycemia have both spinal and vagal origins (Niijima, 1983; Campfield and Smith, 2003; Saberi et al., 2008; Donovan and Watts, 2014). Third, nerve section experiments clearly show that some glucosensing information from the PMV wall reaches the medulla via spinal splanchic sensory nerves rather than the vagus nerve (Fujita and Donovan, 2005; Bohland et al., 2014).

To support these functions those spinal sensory nerves in the splanchnic nerve that terminate in the PMV wall originate in lower thoracic DRGs (T8-T13; Barja et al., 1983; Barja and Mathison, 1984; Fujita and Donovan, 2005; Donovan and Watts, 2014). The significant numbers of H129-infected neurons we see in these same T8-T13 DRGs (Fig. 7) are consistent with these findings. In turn, T8-T13 DRG neurons terminate on lamina I neurons in the dorsal horn of the spinal cord, which then project to the NTS (Menétrey and Basbaum, 1987; Menétrey and De Pommery, 1991). Whether these same dorsal horn neurons project directly into the DMX has yet to be resolved using monosynaptic tracers.

Our results demonstrate that vagal sensory neurons are well positioned to convey chemosensory information from the PMV wall to the DMX. However, the degree to which a spinally-mediated component from the PMV wall is able to do this is less clear. Thus, although we identified H129infected neurons in the same T8-T13 DRGs that innervate the PMV wall, the lack of an available marker that is equivalent to IB4 for spinally originating sensory inputs, means we are unable to unequivocally identify spinally originating terminal appositions in the NTS and DMX. However, it is possible that at least some of the eGFP-Synl co-occurring terminals we find in the NTS and DMX that lack IB4 (Fig. 9) are of this type (Fig. 10B).

\section{Functional aspects}

The PMV is the direct conduit into the liver for nutrients and oxidizable fuels from the small intestine, and for hormones secreted by the gut and pancreas. While liver parenchyma has no known sensory innervation (Berthoud, 2008), the PMV is a unique vascular compartment that contains a wealth of chemosensory information. This includes blood glucose from hypoglycemia to hyperglycemia (Niijima, 1969, 1983, 1989), osmolality (Lechner et al., 2011), natremia (Morita et al., 1990; Morita and Abe, 2011), lipids (Randich et al., 2001; Cox et al., 2004), proteins (Mithieux et al., 2005; Duraffourd et al., 2012), amino acids (Niijima and Meguid, 1995), and the hormones glucagon (Geary, 1990), GLP-1 (Nakabayashi et al., 1996; Balkan and Li, 2000; Vahl et al., 2007), leptin (Shiraishi et al., 1999), and CCK (Horn and Friedman, 2004). Furthermore, the magnitude and dynamics of some of this PMV wall chemosensory information differ from posthepatic locations, for example blood concentrations of glucose (Strubbe and Steffens, 1977), GLP-1 (Deacon et al., 1996; Holst, 2007), and pulsatile insulin secretory patterns (Matveyenko et al., 2008). The ability to convey this type of information from the PMV provides the brain with an additional perspective of the vascular chemosensory components detected either side of the blood-brain barrier.

After it enters the brain, PMV wall chemosensory information influences at least two important functions: food intake, including flavor preference, and glycemia. Both of these functions are influenced by sensory information conveyed vagally and spinally (Novin et al., 1973; Tordoff and Friedman, 1986, 1988; Geary, 1990; Del Prete and Scharrer, 1994; Campfield and Smith, 2003; Fujita and Donovan, 2005; Bohland et al., 2014; Donovan and Watts, 2014; Goswami et al., 2018; Zhang et al., 2018). With this in mind, the robust $\mathrm{H} 129$ infections in the DMX together with the virtual absence of H129 in NTS neurons provide structural support for considering PMV wall chemosensory information as a significant and direct controller of vago-vagal reflexes and possibly spino-vagal reflexes (Fig. 10A). Indeed, the way vagal sensory inputs from the PMV wall to the DMX appear to be organized means that controlling this reflex may be the sole function of vagally conveyed PMV wall chemosensory information, which is directed at least in part toward controlling food intake.

The parasympathetic motor component of the PMV/ vago-vagal reflex, and possibly a PMV/spino-vagal reflex has the capacity to influence a wide range of functions associated with energy balance, including food intake and glycemia. These include the gastrointestinal tract from the lower esophagus to the transverse colon (Berthoud et al., 1991) where postganglionic enteric neurons (Schemann and Grundy, 1992) can, for example, inhibit or excite gastric smooth muscles to exert fine control of gastric tone and motility (Abrahamsson and Jansson, 1973; Rossiter et al., 1990). Parasympathetic motor control also influences pancreatic exocrine (Love et al., 2007) and endocrine function (Buijs et al., 2001; Taborsky and Mundinger, 2012), particularly insulin secretion (Ahrén and Taborsky, 1986; Nagase et al., 1993), a mechanism that may contribute to the hypoglycemic response to HPV hyperglycemia (Burcelin et al., 2000). Interestingly, increases in HPV glucose and GLP-1 increase pancreatic insulin release via a vago-vagal reflex, and they appear to do so synergistically (Nakabayashi et al., 1996; Balkan and Li, 2000; 
Burcelin et al., 2001). The liver also has a parasympathetic motor innervation (Pocai et al., 2005a,b; Lam et al., 2007).

\section{Summary and conclusions}

Our results show that the vast majority of medullary neurons that are the first to receive chemosensory information from the PMV wall are preganglionic parasympathetic neurons in the DMX. The negligible number of NTS neurons that are infected after H129 PMV wall-injections means that vagally conveyed information terminates more or less exclusively on DMX neurons thereby enabling a PMV/vago-vagal/parasympathetic reflex (Fig. 10). This information flow may be augmented by PMV wall sensory inputs that reach the DMX from the spinal cord, meaning that both vagal and spinal routes provide direct inputs to the DMX. Further studies are needed to clarify the details of these inputs, particularly those mediated by projections through the spinal cord.

\section{References}

Abrahamsson H, Jansson G (1973) Reflex vagal inhibition of esophageal motility. Acta Physiol Scand 89:600-602.

Ahrén B, Taborsky GJ (1986) The mechanism of vagal nerve stimulation of glucagon and insulin secretion in the dog. Endocrinology 118:1551-1557.

Akiyoshi H, Gonda T, Terada T (1998) A comparative histochemical and immunohistochemical study of aminergic, cholinergic and peptidergic innervation in rat, hamster, guinea pig, dog and human livers. Liver 18:352-359.

Archin NM, Atherton SS (2002) Rapid spread of a neurovirulent strain of HSV-1 through the CNS of BALB/C mice following anterior chamber inoculation. J Neurovirol 8:122-135.

Arnold M, Dai Y, Tso P, Langhans W (2012) Meal-contingent intestinal lymph sampling from awake, unrestrained rats. Am J Physiol Regul Integr Comp Physiol 302:R1365-R1371.

Balkan B, Li X (2000) Portal GLP-1 administration in rats augments the insulin response to glucose via neuronal mechanisms. Am J Physiol Regul Integr Comp Physiol 279:R1449-R1454.

Barber RP, Phelps PE, Houser CR, Crawford GD, Salvaterra PM, Vaughn JE (1984) The morphology and distribution of neurons containing choline acetyltransferase in the adult rat spinal cord: an immunocytochemical study. J Comp Neurol 229:329-346.

Barja F, Mathison R (1984) Sensory innervation of the rat portal vein and the hepatic artery. J Auton Nerv Syst 10:117-125.

Barja F, Mathison R, Huggel H (1983) Substance P-containing nerve fibres in large peripheral blood vessels of the rat. Cell Tissue Res 229:411-422.

Bartness TJ, Liu Y, Shrestha YB, Ryu V (2014) Neural innervation of white adipose tissue and the control of lipolysis. Front Neuroendocrinol 35:473-493.

Bellier JP, Kimura H (2007) Acetylcholine synthesis by choline acetyltransferase of a peripheral type as demonstrated in adult rat dorsal root ganglion. J Neurochem 101:1607-1618.

Berthoud HR (2004) Anatomy and function of sensory hepatic nerves. Anat Rec A Discov Mol Cell Evol Biol 280:827-835.

Berthoud HR (2008) The vagus nerve, food intake and obesity. Regul Pept 149:15-25.

Berthoud HR, Neuhuber WL (2000) Functional and chemical anatomy of the afferent vagal system. Auton Neurosci 85:1-17.

Berthoud HR, Carlson NR, Powley TL (1991) Topography of efferent vagal innervation of the rat gastrointestinal tract. Am J Physiol 260: R200-R207.

Berthoud HR, Kressel M, Neuhuber WL (1992) An anterograde tracing study of the vagal innervation of rat liver, portal vein and biliary system. Anat Embryol (Berl) 186:431-442.
Bohland M, Matveyenko AV, Saberi M, Khan AM, Watts AG, Donovan CM (2014) Activation of hindbrain neurons is mediated by portal-mesenteric vein glucosensors during slow-onset hypoglycemia. Diabetes 63:2866-2875.

Bourque CW (2008) Central mechanisms of osmosensation and systemic osmoregulation. Nat Rev Neurosci 9:519-531.

Bruinstroop E, Cano G, Vanderhorst VG, Cavalcante JC, Wirth J, Sena-Esteves M, Saper CB (2012) Spinal projections of the A5, A6 (locus coeruleus), and A7 noradrenergic cell groups in rats. J Comp Neurol 520:1985-2001.

Buijs RM, Chun SJ, Niijima A, Romijn HJ, Nagai K (2001) Parasympathetic and sympathetic control of the pancreas: a role for the suprachiasmatic nucleus and other hypothalamic centers that are involved in the regulation of food intake. J Comp Neurol 431:405-423.

Burcelin R, Dolci W, Thorens B (2000) Portal glucose infusion in the mouse induces hypoglycemia: evidence that the hepatoportal glucose sensor stimulates glucose utilization. Diabetes 49:16351642.

Burcelin R, Da Costa A, Drucker D, Thorens B (2001) Glucose competence of the hepatoportal vein sensor requires the presence of an activated glucagon-like peptide-1 receptor. Diabetes 50:17201728.

Campfield LA, Smith FJ (2003) Blood glucose dynamics and control of meal initiation: a pattern detection and recognition theory. Physiol Rev 83:25-58.

Cox JE, Kelm GR, Meller ST, Spraggins DS, Randich A (2004) Truncal and hepatic vagotomy reduce suppression of feeding by jejunal lipid infusions. Physiol Behav 81:29-36.

Deacon CF, Pridal L, Klarskov L, Olesen M, Holst JJ (1996) Glucagon-like peptide 1 undergoes differential tissue-specific metabolism in the anesthetized pig. Am J Physiol 271:E458-E464.

Del Prete E, Scharrer E (1994) Circadian effects of hepatic branch vagotomy on the feeding response to 2-deoxy-D-glucose in rats. $J$ Auton Nerv Syst 46:27-36.

Dennison SJ, Merritt VE, Aprison MH, Felten DL (1981) Redefinition of the location of the dorsal (motor) nucleus of the vagus in the rat. Brain Res Bull 6:77-81.

Dong HM, Ichimura K, Sakai T (2010) Structural organization of hepatic portal vein in rat with special reference to musculature, intimal folds, and endothelial cell alignment. Anat Rec (Hoboken) 293:1887-1895.

Donovan CM, Watts AG (2014) Peripheral and central glucose sensing in hypoglycemic detection. Physiology (Bethesda) 29:314-324.

Donovan CM, Halter JB, Bergman RN (1991a) Importance of hepatic glucoreceptors in sympathoadrenal response to hypoglycemia. Diabetes 40:155-158.

Donovan CM, Cane P, Bergman RN (1991b) Search for the hypoglycemia receptor using the local irrigation approach. Adv Exp Med Biol 291:185-196.

Donovan CM, Hamilton-Wessler M, Halter JB, Bergman RN (1994) Primacy of liver glucosensors in the sympathetic response to progressive hypoglycemia. Proc Natl Acad Sci USA 91:2863-2867.

Dunn KW, Kamocka MM, McDonald JH (2011) A practical guide to evaluating colocalization in biological microscopy. Am J Physiol Cell Physiol 300:C723-C742.

Duraffourd C, De Vadder F, Goncalves D, Delaere F, Penhoat A, Brusset B, Rajas F, Chassard D, Duchampt A, Stefanutti A, Gautier-Stein A, Mithieux G (2012) Mu-opioid receptors and dietary protein stimulate a gut-brain neural circuitry limiting food intake. Cell 150:377-388.

Fox EA, Powley TL (1985) Longitudinal columnar organization within the dorsal motor nucleus represents separate branches of the abdominal vagus. Brain Res 341:269-282.

Fujita S, Donovan CM (2005) Celiac-superior mesenteric ganglionectomy, but not vagotomy, suppresses the sympathoadrenal response to insulin-induced hypoglycemia. Diabetes 54:3258-3264.

Fujita S, Bohland M, Sanchez-Watts G, Watts AG, Donovan CM (2007) Hypoglycemic detection at the portal vein is mediated by 
capsaicin-sensitive primary sensory neurons. Am J Physiol Endocrinol Metab 293:E96-E101.

Geary N (1990) Pancreatic glucagon signals postprandial satiety. Neurosci Biobehav Rev 14:323-338.

Goswami C, Iwasaki Y, Yada T (2018) Short-chain fatty acids suppress food intake by activating vagal afferent neurons. J Nutr Biochem 57:130-135.

Hamilton-Wessler M, Bergman RN, Halter JB, Watanabe RM, Donovan CM (1994) The role of liver glucosensors in the integrated sympathetic response induced by deep hypoglycemia in dogs. Diabetes 43:1052-1060.

Han W, Tellez LA, Perkins MH, Perez IO, Qu T, Ferreira J, Ferreira TL, Quinn D, Liu ZW, Gao XB, Kaelberer MM, Bohórquez DV, Shammah-Lagnado SJ, de Lartigue G, de Araujo IE (2018) A neural circuit for gut-induced reward. Cell 175:887-888.

Hevener AL, Bergman RN, Donovan CM (1997) Novel glucosensor for hypoglycemic detection localized to the portal vein. Diabetes 46:1521-1525.

Holst JJ (2007) The physiology of glucagon-like peptide 1. Physiol Rev 87:1409-1439.

Horn CC, Friedman MI (2004) Separation of hepatic and gastrointestinal signals from the common "hepatic" branch of the vagus. Am J Physiol Regul Integr Comp Physiol 287:R120-R126.

Horn CC, Meyers K, Lim A, Dye M, Pak D, Rinaman L, Yates BJ (2014) Delineation of vagal emetic pathways: intragastric copper sulfate-induced emesis and viral tract tracing in musk shrews. Am J Physiol Regul Integr Comp Physiol 306:R341-R351.

Johnson CS, Bains JS, Watts AG (2018) Neurotransmitter diversity in pre-synaptic terminals located in the parvicellular neuroendocrine paraventricular nucleus of the rat and mouse hypothalamus. $J$ Comp Neurol 526:1287-1306.

Kalia M, Mesulam MM (1980) Brain stem projections of sensory and motor components of the vagus complex in the cat: II. Laryngeal, tracheobronchial, pulmonary, cardiac, and gastrointestinal branches. J Comp Neurol 193:467-508.

Kalia M, Sullivan JM (1982) Brainstem projections of sensory and motor components of the vagus nerve in the rat. J Comp Neurol 211:248-265.

Kim SH, Hadley SH, Maddison M, Patil M, Cha B, Kollarik M, TaylorClark TE (2020) Mapping of sensory nerve subsets within the vagal ganglia and the brainstem using reporter mice for Pirt, TRPV1, 5HT3, and Tac1 expression. eNeuro 7:ENEURO.0494-19.2020.

Kobashi M, Adachi A (1986) Projection of nucleus tractus solitarius units influenced by hepatoportal afferent signal to parabrachial nucleus. J Auton Nerv Syst 16:153-158.

Krieger JP, Arnold M, Pettersen KG, Lossel P, Langhans W, Lee SJ (2016) Knockdown of GLP-1 receptors in vagal afferents affects normal food intake and glycemia. Diabetes 65:34-43.

Krieger JP, Santos da Conceição EP, Sanchez-Watts G, Arnold M, Pettersen KG, Mohammed M, Modica S, Lossel P, Morrison SF, Madden CJ, Watts AG, Langhans W, Lee SJ (2018) Glucagon-like peptide-1 regulates brown adipose tissue thermogenesis via the gut-brain axis in rats. Am J Physiol Regul Integr Comp Physiol 315:R708-R720.

Lam TK, Gutierrez-Juarez R, Pocai A, Bhanot S, Tso P, Schwartz GJ, Rossetti $L$ (2007) Brain glucose metabolism controls the hepatic secretion of triglyceride-rich lipoproteins. Nat Med 13:171-180.

Lechner SG, Markworth S, Poole K, Smith ES, Lapatsina L, Frahm S, May M, Pischke S, Suzuki M, Ibañez-Tallon I, Luft FC, Jordan J, Lewin GR (2011) The molecular and cellular identity of peripheral osmoreceptors. Neuron 69:332-344.

Lee SJ, Krieger JP, Vergara M, Quinn D, McDougle M, de Araujo A, Darling R, Zollinger B, Anderson S, Pan A, Simonnet EJ, Pignalosa A, Arnold M, Singh A, Langhans W, Raybould HE, de Lartigue G (2020) Blunted vagal cocaine- and amphetamine-regulated transcript promotes hyperphagia and weight gain. Cell Rep 30:20282039.e4.

Lo L, Anderson DJ (2011) A Cre-dependent, anterograde transsynaptic viral tracer for mapping output pathways of genetically marked neurons. Neuron 72:938-950.
Love JA, Yi E, Smith TG (2007) Autonomic pathways regulating pancreatic exocrine secretion. Auton Neurosci 133:19-34.

Matveyenko AV, Veldhuis JD, Butler PC (2008) Measurement of pulsatile insulin secretion in the rat: direct sampling from the hepatic portal vein. Am J Physiol Endocrinol Metab 295:E569-E574.

McGovern AE, Davis-Poynter N, Farrell MJ, Mazzone SB (2012) Transneuronal tracing of airways-related sensory circuitry using herpes simplex virus 1, strain H129. Neuroscience 207:148-166.

McGovern AE, Davis-Poynter N, Yang SK, Simmons DG, Farrell MJ, Mazzone SB (2015) Evidence for multiple sensory circuits in the brain arising from the respiratory system: an anterograde viral tract tracing study in rodents. Brain Struct Funct 220:3683-3699.

Menétrey D, Basbaum Al (1987) Spinal and trigeminal projections to the nucleus of the solitary tract: a possible substrate for somatovisceral and viscerovisceral reflex activation. J Comp Neurol 255:439-450.

Menétrey D, De Pommery J (1991) Origins of spinal ascending pathways that reach central areas involved in visceroception and visceronociception in the rat. Eur J Neurosci 3:249-259.

Mithieux G, Misery P, Magnan C, Pillot B, Gautier-Stein A, Bernard C, Rajas F, Zitoun C (2005) Portal sensing of intestinal gluconeogenesis is a mechanistic link in the diminution of food intake induced by diet protein. Cell Metab 2:321-329.

Mizuno K, Ueno Y (2017) Autonomic nervous system and the liver. Hepatol Res 47:160-165.

Morita H, Abe C (2011) Negative feedforward control of body fluid homeostasis by hepatorenal reflex. Hypertens Res 34:895-905.

Morita H, Ohyama H, Hagiike M, Horiba T, Miyake K, Yamanouchi H, Matsushita K, Hosomi H (1990) Effects of portal infusion of hypertonic solution on jejunal electrolyte transport in anesthetized dogs. Am J Physiol 259:R1289-R1294.

Morita H, Yamashita Y, Nishida Y, Tokuda M, Hatase O, Hosomi H (1997) Fos induction in rat brain neurons after stimulation of the hepatoportal Na-sensitive mechanism. Am J Physiol 272:R913R923.

Nagase H, Inoue S, Tanaka K, Takamura Y, Niijima A (1993) Hepatic glucose-sensitive unit regulation of glucose-induced insulin secretion in rats. Physiol Behav 53:139-143.

Nakabayashi H, Nishizawa M, Nakagawa A, Takeda R, Niijima A (1996) Vagal hepatopancreatic reflex effect evoked by intraportal appearance of tGLP-1. Am J Physiol 271:E808-E813.

Neuhuber WL, Sandoz PA (1986) Vagal primary afferent terminals in the dorsal motor nucleus of the rat: are they making monosynaptic contacts on preganglionic efferent neurons? Neurosci Lett 69:126-130.

Niijima A (1969) Afferent impulse discharges from glucoreceptors in the liver of the guinea pig. Ann NY Acad Sci 157:690-700.

Niijima A (1983) Glucose-sensitive afferent nerve fibers in the liver and their role in food intake and blood glucose regulation. J Auton Nerv Syst 9:207-220.

Niijima A (1989) Neural mechanisms in the control of blood glucose concentration. J Nutr 119:833-840.

Niijima A (1996) Role played by vagal hepatic afferents from chemical sensors in the hepatic-portal region: an electrophysiological study. In: Liver innervation (Shimazu T, ed), pp 323-331. London: John Liberty and Company Ltd.

Niijima A, Meguid MM (1995) An electrophysiological study on amino acid sensors in the hepato-portal system in the rat. Obes Res 3 [Suppl 5]:741S-745S.

Novin D, VanderWeele DA, Rezek M (1973) Infusion of 2-deoxy-Dglucose into the hepatic-portal system causes eating: evidence for peripheral glucoreceptors. Science 181:858-860.

Pocai A, Obici S, Schwartz GJ, Rossetti L (2005a) A brain-liver circuit regulates glucose homeostasis. Cell Metab 1:53-61.

Pocai A, Lam TK, Gutierrez-Juarez R, Obici S, Schwartz GJ, Bryan J, Aguilar-Bryan L, Rossetti L (2005b) Hypothalamic K(ATP) channels control hepatic glucose production. Nature 434:1026-1031.

Randich A, Spraggins DS, Cox JE, Meller ST, Kelm GR (2001) Jejunal or portal vein infusions of lipids increase hepatic vagal afferent activity. Neuroreport 12:3101-3105. 
Reilly FD, McCuskey PA, McCuskey RS (1978) Intrahepatic distribution of nerves in the rat. Anat Rec 191:55-67.

Renehan WE, Zhang X, Beierwaltes WH, Fogel R (1995) Neurons in the dorsal motor nucleus of the vagus may integrate vagal and spinal information from the GI tract. Am J Physiol 268:G780-G790.

Rinaman L (2001) Postnatal development of catecholamine inputs to the paraventricular nucleus of the hypothalamus in rats. J Comp Neurol 438:411-422.

Rinaman L, Schwartz G (2004) Anterograde transneuronal viral tracing of central viscerosensory pathways in rats. J Neurosci 24:2782-2786.

Rinaman L, Card JP, Schwaber JS, Miselis RR (1989) Ultrastructural demonstration of a gastric monosynaptic vagal circuit in the nucleus of the solitary tract in rat. J Neurosci 9:1985-1996.

Rogers RC, Hermann GE (1983) Central connections of the hepatic branch of the vagus nerve: a horseradish peroxidase histochemical study. J Auton Nerv Syst 7:165-174.

Rossiter CD, Norman WP, Jain M, Hornby PJ, Benjamin S, Gillis RA (1990) Control of lower esophageal sphincter pressure by two sites in dorsal motor nucleus of the vagus. Am J Physiol 259: G899-G906.

Ruggiero DA, Giuliano R, Anwar M, Stornetta R, Reis DJ (1990) Anatomical substrates of cholinergic-autonomic regulation in the rat. J Comp Neurol 292:1-53.

Ryu V, Watts AG, Xue B, Bartness TJ (2017) Bidirectional crosstalk between the sensory and sympathetic motor systems innervating brown and white adipose tissue in male Siberian hamsters. Am J Physiol Regul Integr Comp Physiol 312:R324-R337.

Saberi M, Bohland M, Donovan CM (2008) The locus for hypoglycemic detection shifts with the rate of fall in glycemia: the role of portal-superior mesenteric vein glucose sensing. Diabetes 57:13801386.

Sauter JF, Niijima A, Berthoud HR, Jeanrenaud B (1983) Vagal neurons and pathways to the rat's lower viscera: an electrophysiological study. Brain Res Bull 11:487-491.

Schemann M, Grundy D (1992) Electrophysiological identification of vagally innervated enteric neurons in guinea pig stomach. Am J Physiol 263:G709-G718.

Schäfer MK, Eiden LE, Weihe E (1998) Cholinergic neurons and terminal fields revealed by immunohistochemistry for the vesicular acetylcholine transporter. II. The peripheral nervous system. Neuroscience 84:361-376.
Shapiro RE, Miselis RR (1985) The central organization of the vagus nerve innervating the stomach of the rat. J Comp Neurol 238:473488.

Shiraishi T, Sasaki K, Niijima A, Oomura Y (1999) Leptin effects on feeding-related hypothalamic and peripheral neuronal activities in normal and obese rats. Nutrition 15:576-579.

Song CK, Schwartz GJ, Bartness TJ (2009) Anterograde transneuronal viral tract tracing reveals central sensory circuits from white adipose tissue. Am J Physiol Regul Integr Comp Physiol 296: R501-R511.

Strubbe JH, Steffens AB (1977) Blood glucose levels in portal and peripheral circulation and their relation to food intake in the rat. Physiol Behav 19:303-307.

Swanson LW (2018) Brain maps 4.0-Structure of the rat brain: an open access atlas with global nervous system nomenclature ontology and flatmaps. J Comp Neurol 526:935-943.

Taborsky GJ, Mundinger TO (2012) Minireview: the role of the autonomic nervous system in mediating the glucagon response to hypoglycemia. Endocrinology 153:1055-1062.

Tordoff MG, Friedman MI (1986) Hepatic portal glucose infusions decrease food intake and increase food preference. Am J Physiol 251:R192-R196.

Tordoff MG, Friedman MI (1988) Hepatic control of feeding: effect of glucose, fructose, and mannitol infusion. Am J Physiol 254:R969R976.

Vahl TP, Tauchi M, Durler TS, Elfers EE, Fernandes TM, Bitner RD, Ellis KS, Woods SC, Seeley RJ, Herman JP, D'Alessio DA (2007) Glucagon-like peptide-1 (GLP-1) receptors expressed on nerve terminals in the portal vein mediate the effects of endogenous GLP-1 on glucose tolerance in rats. Endocrinology 148:49654973.

Wojaczynski GJ, Engel EA, Steren KE, Enquist LW, Patrick Card J (2015) The neuroinvasive profiles of H129 (herpes simplex virus type 1) recombinants with putative anterograde-only transneuronal spread properties. Brain Struct Funct 220:1395-1420.

Wosnitzka E, Nan X, Nan J, Chacón-Fernández P, Kussmaul L, Schuler M, Hengerer B, Barde YA (2020) A new mouse line reporting the translation of brain-derived neurotrophic factor using green fluorescent protein. eNeuro 7:ENEURO.0462-19.2019.

Zhang L, Han W, Lin C, Li F, de Araujo IE (2018) Sugar metabolism regulates flavor preferences and portal glucose sensing. Front Integr Neurosci 12:57. 